\title{
Supporting Information for Redefining Protein Interfaces within Protein Single Crystals with DNA
}

\author{
Benjamin E. Partridge, Peter H. Winegar, Zhenyu Han, and Chad A. Mirkin*
}

Department of Chemistry and International Institute for Nanotechnology, Northwestern University, 2145 Sheridan Road, Evanston, Illinois, 60208.

*Email: chadnano@northwestern.edu

\section{Table of Contents}

1. Synthesis and Characterization of Mannose- and Galactose-Squaramides ................................................S2

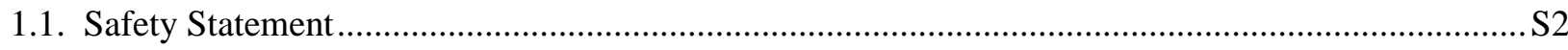

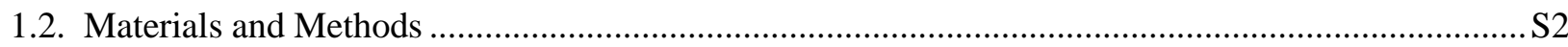

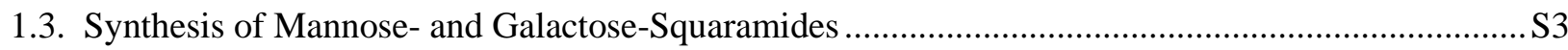

1.4. ${ }^{1} \mathrm{H}$ and ${ }^{13} \mathrm{C}$ NMR Spectra of Man-8, Gal-8, and Intermediate Compounds....................................S7

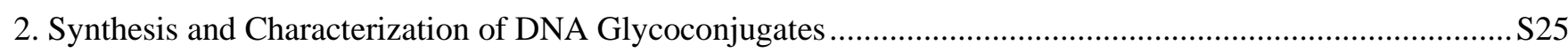

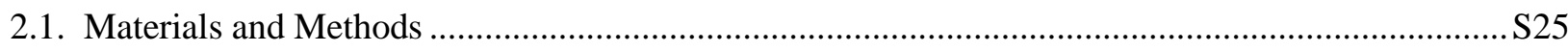

2.2. Synthesis of Amine-Functionalized Oligonucleotides ...........................................................S25

2.3. Conjugation of Sugar-Squaramides to Oligonucleotides ...........................................................S27

2.4. Determination of Extinction Coefficient for Squaramide Linker ................................................S28

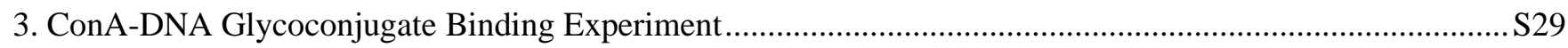

4. Structural Analysis of Single Crystals of ConA and DNA Glycoconjugates...............................................S30

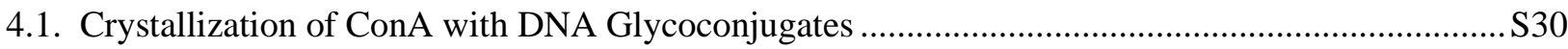

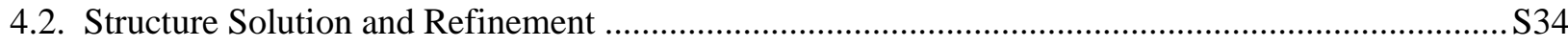

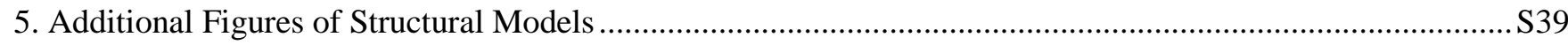

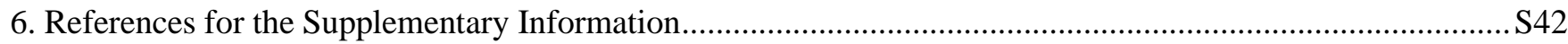




\section{Synthesis and Characterization of Mannose- and Galactose-Squaramides}

\subsection{Safety Statement}

All procedures described in this work should be conducted under adequate supervision by appropriately trained personnel. Two reagents have safety hazards of particular note:

Sodium azide (used in the conversion of $\mathbf{1}$ to $\mathbf{2}$ ) can form explosive metal azides when in contact with heavy metals. Therefore the use of metal equipment (e.g. metal spatulas, uncoated metallic stirrer bars) should be avoided.

Palladium on carbon $(\mathrm{Pd} / \mathrm{C}$ ) (used in the conversion of $\mathbf{5}$ to $\mathbf{6}$ ) is a pyrophoric solid that can spontaneously ignite, especially in the presence of flammable liquids (e.g. ethyl acetate, ethanol). $\mathrm{Pd} / \mathrm{C}$ should only be added to a reaction flask that has been thoroughly purged with $\mathrm{N}_{2}$. Addition as a slurry in a non-flammable solvent (e.g. dichloromethane) reduces the likelihood of ignition, but caution should still be exercised upon addition of flammable solvents.

\subsection{Materials and Methods}

Materials. 2-(2-Chloroethoxy)ethanol (Alfa Aesar), 1,2,3,4,6-penta- $O$-acetyl- $\alpha$-D-mannopyranose (Man-3, Carbosynth), 1,2,3,4,6-penta- $O$-acetyl- $\beta$-D-galactopyranose (Gal-3, Carbosynth), dimethyl squarate (7, TCI America), sodium iodide (Fisher), sodium azide (Fisher), $\mathrm{BF}_{3} \cdot \mathrm{Et}_{2} \mathrm{O}$ (Fisher), methanolic NaOMe solution (Acros), $\mathrm{Pd} / \mathrm{C}$ (Aldrich), and Amberlite IR $120 \mathrm{H}^{+}$resin (Acros) were used as received. rt denotes ambient room temperature, typically $23{ }^{\circ} \mathrm{C}$.

Column chromatography. Chromatography was conducted using a CombiFlash Rf 200 flash chromatography system (Teledyne ISCO) using RediSep Gold columns pre-packed with silica gel (Teledyne ISCO). Elution of desired products was monitored using absorption at $240 \mathrm{~nm}$ or $254 \mathrm{~nm}$. Fractions were visualized by thin-layer chromatography on silica gel plates using cerium ammonium molybdate stain.

Nuclear magnetic resonance (NMR) spectroscopy. NMR spectra were recorded on a Bruker Avance III HD system equipped with a TXO Prodigy probe at $298 \mathrm{~K}$ using the solvent indicated. ${ }^{1} \mathrm{H}$ spectra were referenced to trimethylsilane (TMS, $\delta=0 \mathrm{ppm}$ ) and ${ }^{13} \mathrm{C}$ spectra were referenced to the signal arising from residual solvent. Mass spectrometry. High resolution mass spectrometry (HRMS) data were recorded using a Bruker Impact II QTOF High Resolution Time of Flight mass spectrometer connected to a Bruker Elute UHPLC. Samples were injected via flow analysis using a flow of $0.3 \mathrm{~mL} / \mathrm{min}$ of 5:95 water:acetonitrile with $0.1 \%$ formic acid. 


\subsection{Synthesis of Mannose- and Galactose-Squaramides}

\section{Scheme S1. Synthesis of Mannose-Squaramide (Man-8)}
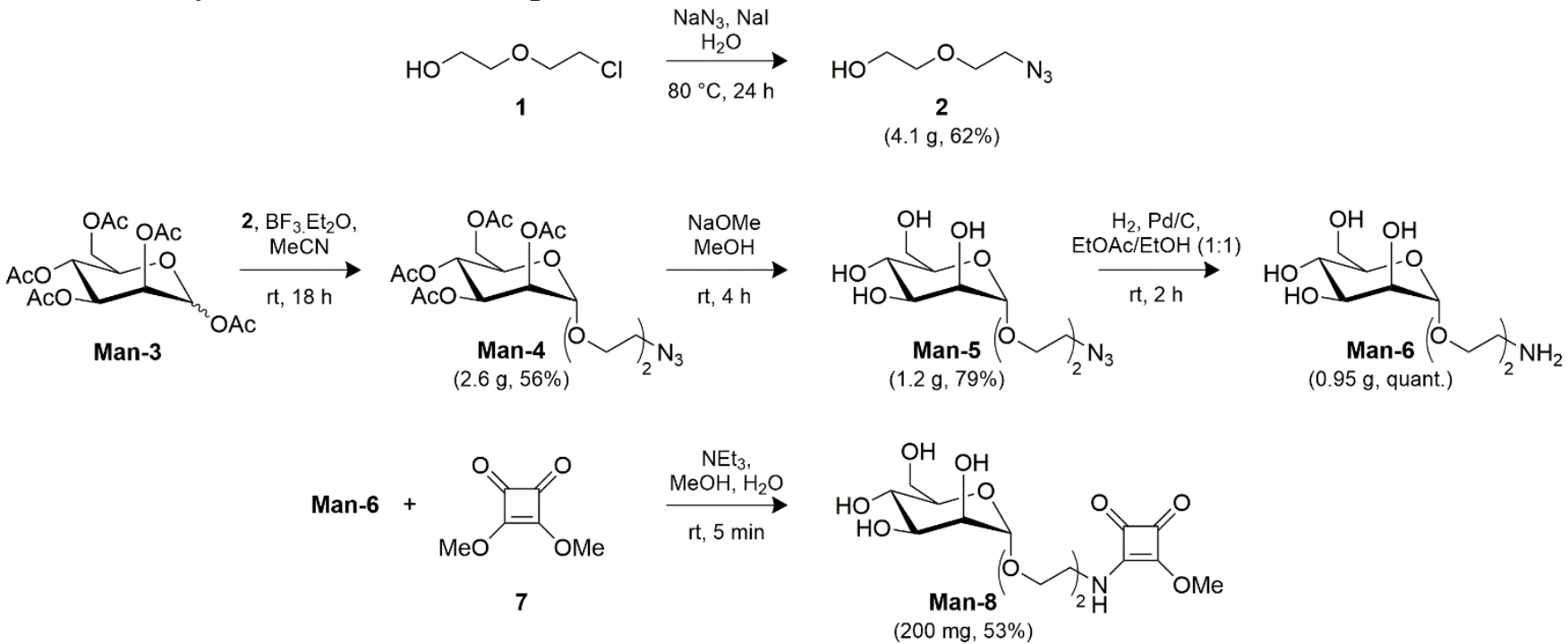

HO $\sim \mathrm{N}_{\mathrm{N}_{3}}$

2-(2-Azidoethoxy)ethanol (2). ${ }^{1}$ To a solution of 2-(2-chloroethoxy)ethanol (1) (7.9 mL, $\left.75 \mathrm{mmol}\right)$ in deionized water $(45 \mathrm{~mL})$ were added sodium azide $(14.63 \mathrm{~g}, 225 \mathrm{mmol}, 3$ equiv) and sodium iodide $(1.12 \mathrm{~g}, 7.5 \mathrm{mmol}, 0.1$ equiv). The mixture was heated to $80{ }^{\circ} \mathrm{C}$, whereupon it was stirred for $15 \mathrm{~h}$. The mixture was allowed to cool to $\mathrm{rt}$ and poured into $\mathrm{NaOH}$ solution $(5 \%$ w/v aq., $75 \mathrm{~mL}) . \mathrm{NaCl}(15 \mathrm{~g})$ was added. The mixture was extracted with diethyl ether $(75 \mathrm{~mL} \times 4)$. The combined organics were dried $\left(\mathrm{MgSO}_{4}\right)$, filtered, and concentrated in vacuo to give 2 as a colorless oil ( $8.22 \mathrm{~g}, 84 \%$ yield $)$.

${ }^{1} \mathrm{H}$ NMR $\left(\mathrm{CDCl}_{3}, 400 \mathrm{MHz}\right): \delta 3.79-3.72(\mathrm{~m}, 2 \mathrm{H}), 3.72-3.67(\mathrm{~m}, 2 \mathrm{H}), 3.63-3.59(\mathrm{~m}, 2 \mathrm{H}), 3.41(\mathrm{t}, J=5.0 \mathrm{~Hz}$, 2H). ${ }^{13} \mathrm{C}\left\{{ }^{1} \mathrm{H}\right\}$ NMR $\left(\mathrm{CDCl}_{3}, 101 \mathrm{MHz}\right): \delta 72.5,70.1,61.8,50.8 . \mathrm{HRMS}(\mathrm{ESI} / \mathrm{LC}-\mathrm{TOF}) \mathrm{m} / \mathrm{z}$ : $[\mathrm{M}+\mathrm{Na}]^{+}$calcd for $\mathrm{C}_{4} \mathrm{H}_{9} \mathrm{~N}_{3} \mathrm{O}_{2} \mathrm{Na}$ 154.0587; found 154.0585.

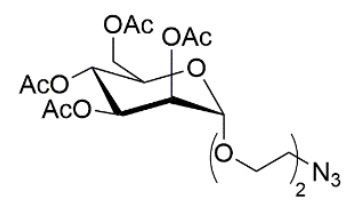

1-O-(2-(2-Azidoethoxy)ethyl)-2,3,4,6-tetra- $O$-acetyl-D-mannopyranose (Man-4). ${ }^{2,3}$ 1,2,3,4,6-Penta- $O$-acetyla-D-mannopyranose (Man-3) (4.76 g, $12.2 \mathrm{mmol})$ and azide 2 (3.20 g, $24.4 \mathrm{mmol}, 2$ equiv) were dissolved in acetonitrile $(60 \mathrm{~mL})$ and the solution cooled to $0{ }^{\circ} \mathrm{C} . \mathrm{BF}_{3} \cdot \mathrm{Et}_{2} \mathrm{O}(3.31 \mathrm{~mL}, 26.8 \mathrm{mmol}, 2.2$ equiv) was added dropwise. The solution was allowed to warm to $\mathrm{rt}$ whereupon it was stirred for $20 \mathrm{~h}$. The reaction mixture was quenched by addition of $\mathrm{NaHCO}_{3}$ solution (sat. aq., $\left.75 \mathrm{~mL}\right)$ and extracted with diethyl ether $(60 \mathrm{~mL} \times 4)$. The combined organics were washed with $\mathrm{NaHCO}_{3}$ solution (sat. aq., $\left.60 \mathrm{~mL} \times 2\right), \mathrm{H}_{2} \mathrm{O}(60 \mathrm{~mL})$, and brine $(60 \mathrm{~mL})$, then dried $\left(\mathrm{MgSO}_{4}\right)$, filtered, and concentrated in vасио. The residue was purified by flash column chromatography on silica gel (eluent: 0-100\% EtOAc in hexanes) to give Man-4 as a colorless oil (2.55 g, 45\% yield). 
${ }^{1} \mathrm{H}$ NMR $\left(\mathrm{CDCl}_{3}, 400 \mathrm{MHz}\right): \delta 5.37(\mathrm{dd}, J=10.0,3.4 \mathrm{~Hz}, 1 \mathrm{H}), 5.32-5.24(\mathrm{~m}, 2 \mathrm{H}), 4.88(\mathrm{~d}, J=1.8 \mathrm{~Hz}, 1 \mathrm{H}), 4.29$ $(\mathrm{dd}, J=12.5,5.3 \mathrm{~Hz}, 1 \mathrm{H}), 4.15-4.03(\mathrm{~m}, 2 \mathrm{H}), 3.88-3.79(\mathrm{~m}, 1 \mathrm{H}), 3.68(\mathrm{td}, J=5.2,2.5 \mathrm{~Hz}, 5 \mathrm{H}), 3.43-3.37(\mathrm{~m}, 2 \mathrm{H})$, $2.15(\mathrm{~s}, 3 \mathrm{H}), 2.10(\mathrm{~s}, 3 \mathrm{H}), 2.04(\mathrm{~s}, 3 \mathrm{H}), 1.99(\mathrm{~s}, 3 \mathrm{H}) .{ }^{13} \mathrm{C}\left\{{ }^{1} \mathrm{H}\right\} \mathrm{NMR}\left(\mathrm{CDCl}_{3}, 101 \mathrm{MHz}\right): \delta$ 170.8, 170.2, 170.1, 169.9, 97.9, 70.4, 70.2, 69.7, 69.2, 68.6, 67.5, 66.3, 62.6, 50.9, 21.0, 20.9, 20.8, 20.8. (ESI/LC-TOF) m/z: [M + $\mathrm{Na}]^{+}$calcd for $\mathrm{C}_{18} \mathrm{H}_{27} \mathrm{~N}_{3} \mathrm{O}_{11} \mathrm{Na} 484.1538$; found 484.1531 .

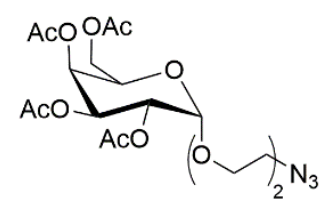

1-O-(2-(2-Azidoethoxy)ethyl)-2,3,4,6-tetra- $O$-acetyl-D-galactopyranose (Gal-4). Gal-4 was prepared analogously to Man-4, starting from 1,2,3,4,6-penta- $O$-acetyl- $\beta$-D-galactopyranose (Gal-3) (4.76 g, 12.2 mmol), azide $2(3.20 \mathrm{~g}, 24.4 \mathrm{mmol})$, and $\mathrm{BF}_{3} \cdot \mathrm{Et}_{2} \mathrm{O}(3.31 \mathrm{~mL}, 26.8 \mathrm{mmol})$, to give Gal-4 as a colorless oil $(3.60 \mathrm{~g}, 64 \%$ yield).

${ }^{1} \mathrm{H}$ NMR (CD $\left.3 \mathrm{OD}, 400 \mathrm{MHz}\right): \delta 5.41-5.36(\mathrm{~m}, 1 \mathrm{H}), 5.15-5.05(\mathrm{~m}, 2 \mathrm{H}), 4.74-4.67(\mathrm{~m}, 1 \mathrm{H}), 4.20-4.06(\mathrm{~m}, 3 \mathrm{H})$, $3.94(\mathrm{dt}, J=11.2,4.0 \mathrm{~Hz}, 1 \mathrm{H}), 3.76(\mathrm{ddd}, J=11.2,6.2,4.1 \mathrm{~Hz}, 1 \mathrm{H}), 3.66(\mathrm{t}, J=4.8 \mathrm{~Hz}, 4 \mathrm{H}), 3.37(\mathrm{td}, J=4.7$, $1.9 \mathrm{~Hz}, 2 \mathrm{H}), 2.14(\mathrm{~s}, 3 \mathrm{H}), 2.06(\mathrm{~s}, 3 \mathrm{H}), 2.03(\mathrm{~s}, 3 \mathrm{H}), 1.95(\mathrm{~s}, 3 \mathrm{H}) .{ }^{13} \mathrm{C}\left\{{ }^{1} \mathrm{H}\right\} \mathrm{NMR}\left(\mathrm{CD}_{3} \mathrm{OD}, 101 \mathrm{MHz}\right): \delta 172.1$, 172.0, 171.5, 171.4, 102.3, 72.4, 71.8, 71.4, 71.2, 70.5, 70.2, 68.9, 62.6, 51.9, 20.7, 20.6, 20.5, 20.5. HRMS (ESI/LC-TOF) m/z: [M + Na] $]^{+}$calcd for $\mathrm{C}_{18} \mathrm{H}_{27} \mathrm{~N}_{3} \mathrm{O}_{11} \mathrm{Na} 484.1538$; found 484.1542.

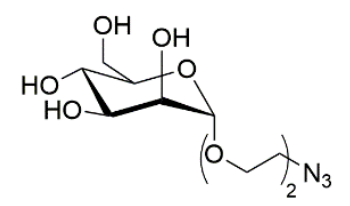

1-O-(2-(2-Azidoethoxy)ethyl)-D-mannopyranose (Man-5).,3 To a solution of Man-4 (2.53 g, $5.48 \mathrm{mmol})$ in methanol $(30 \mathrm{~mL})$ was added $\mathrm{NaOMe}(25 \mathrm{wt} \%$ in $\mathrm{MeOH}, 6.23 \mathrm{~mL}, 27.4 \mathrm{mmol}, 5$ equiv). The reaction was monitored by TLC $\left(1: 9 \mathrm{v} / \mathrm{v} \mathrm{MeOH} / \mathrm{CH}_{2} \mathrm{Cl}_{2}\right)$. Once complete $(\sim 3 \mathrm{~h})$, the mixture was diluted with $\mathrm{MeOH}(45 \mathrm{~mL})$ and neutralized by addition of Amberlite IR $120 \mathrm{H}^{+}$resin (about $20 \mathrm{~g}$ ). The mixture was filtered through a Celite plug and washed thoroughly with $\mathrm{MeOH}$. The orange filtrate was concentrated in vacuo. Residual water was removed by azeotropic distillation at reduced pressure with toluene $(\sim 100 \mathrm{~mL})$. The resultant dark orange oil was purified by flash column chromatography on silica gel (eluent: $0-100 \% \mathrm{MeOH}$ in $\mathrm{CH}_{2} \mathrm{Cl}_{2}$ ) to give $\mathbf{M a n - 5}$ as a colorless oil ( $1.40 \mathrm{~g}, 87 \%$ yield).

${ }^{1} \mathrm{H}$ NMR (D $\left.2 \mathrm{O}, 400 \mathrm{MHz}\right): \delta 4.92(\mathrm{~d}, J=1.7 \mathrm{~Hz}, 1 \mathrm{H}), 4.00(\mathrm{dd}, J=3.4,1.7 \mathrm{~Hz}, 1 \mathrm{H}), 3.96-3.92(\mathrm{~m}, 1 \mathrm{H}), 3.91(\mathrm{t}$, $J=3.2 \mathrm{~Hz}, 1 \mathrm{H}), 3.89-3.84(\mathrm{~m}, 1 \mathrm{H}), 3.79(\mathrm{~m}, 5 \mathrm{H}), 3.76-3.67$ (overlapping $\mathrm{m}, 3 \mathrm{H}), 3.53(\mathrm{dd}, \mathrm{J}=5.5,4.2 \mathrm{~Hz}$, $2 \mathrm{H}) .{ }^{13} \mathrm{C}\left\{{ }^{1} \mathrm{H}\right\}$ NMR $\left(\mathrm{D}_{2} \mathrm{O}, 101 \mathrm{MHz}\right): \delta 100.0,72.7,70.5,70.0,69.4,69.3,66.7,66.4,60.9,50.1$. HRMS (ESI/LC-TOF) m/z: [M+ Na $]^{+}$calcd for $\mathrm{C}_{10} \mathrm{H}_{19} \mathrm{~N}_{3} \mathrm{O}_{7} \mathrm{Na} 316.1115$; found 316.1111 . 


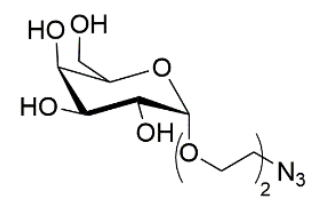

1-O-(2-(2-Azidoethoxy)ethyl)-D-galactopyranose (Gal-5). Gal-5 was prepared analogously to Man-5, starting from Gal-4 (3.58 g, $7.76 \mathrm{mmol}$ ) and NaOMe (25 wt\% in MeOH, $8.82 \mathrm{~mL}, 38.8 \mathrm{mmol}$ ), to give Gal-5 as a colorless oil (1.91 g, 84\% yield).

${ }^{1} \mathrm{H}$ NMR (D $\left.\mathrm{D}_{2} \mathrm{O}, 400 \mathrm{MHz}\right): \delta 4.46(\mathrm{~d}, J=7.9 \mathrm{~Hz}, 1 \mathrm{H}), 4.11(\mathrm{dt}, J=11.2,4.2 \mathrm{~Hz}, 1 \mathrm{H}), 3.95(\mathrm{~d}, J=3.4 \mathrm{~Hz}, 1 \mathrm{H})$, 3.91-3.84 (m, 1H), 3.84-3.75 (overlapping m, 6H), 3.70 (overlapping m, 2H), 3.61-3.52 (m, 3H). ${ }^{13} \mathrm{C}\left\{{ }^{1} \mathrm{H}\right\} \mathrm{NMR}$ $\left(\mathrm{D}_{2} \mathrm{O}, 101 \mathrm{MHz}\right): \delta 102.9,75.1,72.7,70.8,69.7,69.1,68.7,68.6,61.0,50.2 . \mathrm{HRMS}(\mathrm{ESI} / \mathrm{LC}-\mathrm{TOF}) \mathrm{m} / \mathrm{z}:[\mathrm{M}+$ $\mathrm{Na}]^{+}$calcd for $\mathrm{C}_{10} \mathrm{H}_{19} \mathrm{~N}_{3} \mathrm{O}_{7} \mathrm{Na} 316.1115$; found 316.1104.

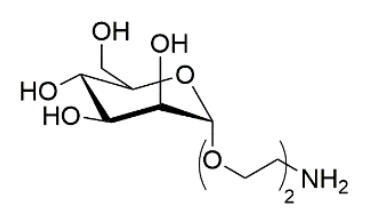

1-O-(2-(2-Aminoethoxy)ethyl)-D-mannopyranose (Man-6). ${ }^{4}$ A $250-\mathrm{mL}$ round-bottomed flask was charged with Man-5 (1.37 g, $5.58 \mathrm{mmol})$ and a magnetic stirrer bar, evacuated, and backfilled with $\mathrm{N}_{2}$ three times. Pd/C (10 wt\% $\mathrm{Pd}, 137 \mathrm{mg}, 10 \% \mathrm{w} / \mathrm{w})$ was added as a slurry in $\mathrm{CH}_{2} \mathrm{Cl}_{2}(2 \mathrm{~mL})$, followed by EtOAc $(30 \mathrm{~mL})$ and $\mathrm{EtOH}(30 \mathrm{~mL})$. The mixture was placed under a dynamic $\mathrm{H}_{2}$ atmosphere and stirred vigorously at $\mathrm{rt}$. The reaction was monitored by TLC $\left(1: 1 \mathrm{v} / \mathrm{v} \mathrm{MeOH} / \mathrm{CH}_{2} \mathrm{Cl}_{2}\right)$. Once complete $(\sim 2 \mathrm{~h})$, the mixture was filtered through a Celite plug and washed thoroughly with a mixture of EtOAc and EtOH (1:1 v/v). The filtrate was concentrated in vacuo to give Man-6 as a white foamy solid (1.10 g, 88\% yield).

${ }^{1} \mathrm{H}$ NMR (CD $\left.{ }_{3} \mathrm{OD}, 400 \mathrm{MHz}\right): \delta 4.74(\mathrm{~d}, J=1.7 \mathrm{~Hz}, 1 \mathrm{H}), 3.83-3.72(\mathrm{~m}, 3 \mathrm{H}), 3.69-3.49$ (overlapping m, 9H), 3.49$3.42(\mathrm{~m}, 1 \mathrm{H}), 3.25(\mathrm{p}, J=1.6 \mathrm{~Hz}, 3 \mathrm{H}), 2.72(\mathrm{t}, J=5.3 \mathrm{~Hz}, 1 \mathrm{H}) .{ }^{13} \mathrm{C}\left\{{ }^{1} \mathrm{H}\right\} \mathrm{NMR}\left(\mathrm{CD}_{3} \mathrm{OD}, 101 \mathrm{MHz}\right): \delta 101.7,74.7$, 73.5, 72.6, 72.1, 71.2, 68.7, 67.8, 63.0, 42.1. HRMS (ESI/LC-TOF) m/z: $[\mathrm{M}+\mathrm{Na}]^{+}$calcd for $\mathrm{C}_{10} \mathrm{H}_{22} \mathrm{NO}_{7} \mathrm{Na}$ 268.1391; found 268.1386.

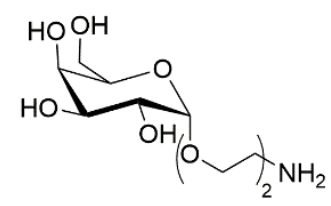

1-O-(2-(2-Aminoethoxy)ethyl)-D-galactopyranose (Gal-6). Gal-6 was prepared analogously to Man-6, starting from Gal-5 (1.88 g, $7.67 \mathrm{mmol})$ and Pd/C (10 wt\% Pd, $188 \mathrm{mg})$, to give Gal-6 as a white foamy solid (1.30 g, 76\% yield).

${ }^{1} \mathrm{H}$ NMR (CD $\left.\mathrm{CD}_{3} \mathrm{OD} 400 \mathrm{MHz}\right): \delta 4.21(\mathrm{dd}, J=7.5,2.5 \mathrm{~Hz}, 1 \mathrm{H}), 3.96(\mathrm{ddd}, J=10.7,5.2,3.9 \mathrm{~Hz}, 1 \mathrm{H}), 3.76(\mathrm{dd}, J=$ 3.3, 1.3 Hz, 1H), 3.74-3.59 (overlapping m, 6H), 3.52-3.37 (overlapping m, 4H), 3.25 (p, J = 1.7 Hz, 2H), 2.73 (t, $J=5.3 \mathrm{~Hz}, 1 \mathrm{H}) .{ }^{13} \mathrm{C}\left\{{ }^{1} \mathrm{H}\right\} \mathrm{NMR}\left(\mathrm{CD}_{3} \mathrm{OD}, 101 \mathrm{MHz}\right): \delta 105.1,76.7,75.0,73.3,72.5,71.2,70.3,69.7,62.5,42.0$. HRMS (ESI/LC-TOF) m/z: [M + Na $]^{+}$calcd for $\mathrm{C}_{10} \mathrm{H}_{22} \mathrm{NO}_{7} \mathrm{Na} 268.1391$; found 268.1383. 


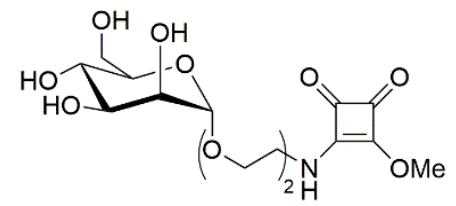

1-O-(2-(Methyl 2-squaramidoethoxy)ethyl)-D-mannopyranose (Man-8). ${ }^{5,6}$ To a solution of Man-6 (267 mg, 1.0 $\mathrm{mmol})$ in deionized water $(1 \mathrm{~mL})$ were added $\mathrm{MeOH}(16 \mathrm{~mL})$, triethylamine $(60 \mu \mathrm{L})$, and dimethyl squarate $(7)$ (426 mg, $3.0 \mathrm{mmol}, 3$ equiv). The solution was stirred at $\mathrm{rt}$ for $10 \mathrm{~min}$. MeOH was removed in vacuo and residual water was removed by azeotropic distillation at reduced pressure with toluene $(\sim 40 \mathrm{~mL})$. The resultant residue was purified by flash column chromatography on silica gel (eluent: 0-30\% $\mathrm{MeOH}$ in $\mathrm{CH}_{2} \mathrm{Cl}_{2}$ ) to give Man-8 as a colorless oil (150 mg, $40 \%$ yield).

${ }^{1} \mathrm{H}$ NMR (CD $\mathrm{OD}, 400 \mathrm{MHz}$ ): $\delta 4.80$ (s, 1H), 4.39 (overlapping s, 3H), 3.91-3.76 (overlapping m, 4H), 3.76-3.53 (overlapping m, 10H), $3.37(\mathrm{~s}, 1 \mathrm{H}) .{ }^{13} \mathrm{C}\left\{{ }^{1} \mathrm{H}\right\} \mathrm{NMR}\left(\mathrm{CD}_{3} \mathrm{OD}, 101 \mathrm{MHz}\right): \delta 185.1,178.6,101.7,74.6,72.6,72.1$, 71.4, 71.2, 71.1, 68.6, 67.8, 63.0, 61.2, 45.6, 45.1. HRMS (ESI/LC-TOF) m/z: $[\mathrm{M}+\mathrm{Na}]^{+}$calcd for $\mathrm{C}_{15} \mathrm{H}_{23} \mathrm{NO}_{10} \mathrm{Na}$ 400.1214; found 400.1214 .

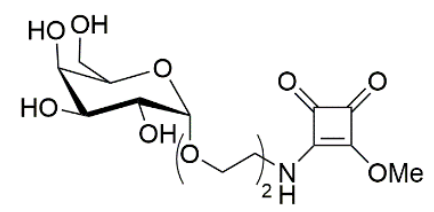

1-O-(2-(Methyl 2-squaramidoethoxy)ethyl)-D-galactopyranose (Gal-8). Gal-8 was prepared analogously to Man-8, starting from Gal-6 (267 mg, $1.0 \mathrm{mmol}$ ) and dimethyl squarate (7) (426 mg, $3.0 \mathrm{mmol}$ ), to give Gal-8 as a colorless oil (100 mg, 27\% yield).

${ }^{1} \mathrm{H}$ NMR (CD $\left.{ }_{3} \mathrm{OD}, 400 \mathrm{MHz}\right): \delta 4.39$ (overlapping s, 3H), 4.29 (d, $\left.J=7.3 \mathrm{~Hz}, 1 \mathrm{H}\right), 4.06-3.96$ (m, $\left.1 \mathrm{H}\right), 3.84$ (dd, $J$ = 3.2, $1.1 \mathrm{~Hz}, 1 \mathrm{H}$ ), 3.82-3.64 (overlapping $\mathrm{m}, 8 \mathrm{H}$ ), 3.60 (t, $J=5.0 \mathrm{~Hz}, 1 \mathrm{H}$ ), 3.57-3.47 (overlapping m, $3 \mathrm{H}$ ), 3.37 (s, 1H). ${ }^{13} \mathrm{C}\left\{{ }^{1} \mathrm{H}\right\}$ NMR $\left(\mathrm{CD}_{3} \mathrm{OD}, 101 \mathrm{MHz}\right): \delta 186.7,180.0,105.1,76.8,75.0,72.5,71.4,71.4,71.3,70.9,70.3$, 69.9, 62.5, 45.5, 45.1. HRMS (ESI/LC-TOF) m/z: [M + Na] $]^{+}$calcd for $\mathrm{C}_{15} \mathrm{H}_{23} \mathrm{NO}_{10} \mathrm{Na}$ 400.1214; found 400.1211. 
1.4. ${ }^{1} \mathrm{H}$ and ${ }^{13} \mathrm{C}$ NMR Spectra of Man-8, Gal-8, and Intermediate Compounds

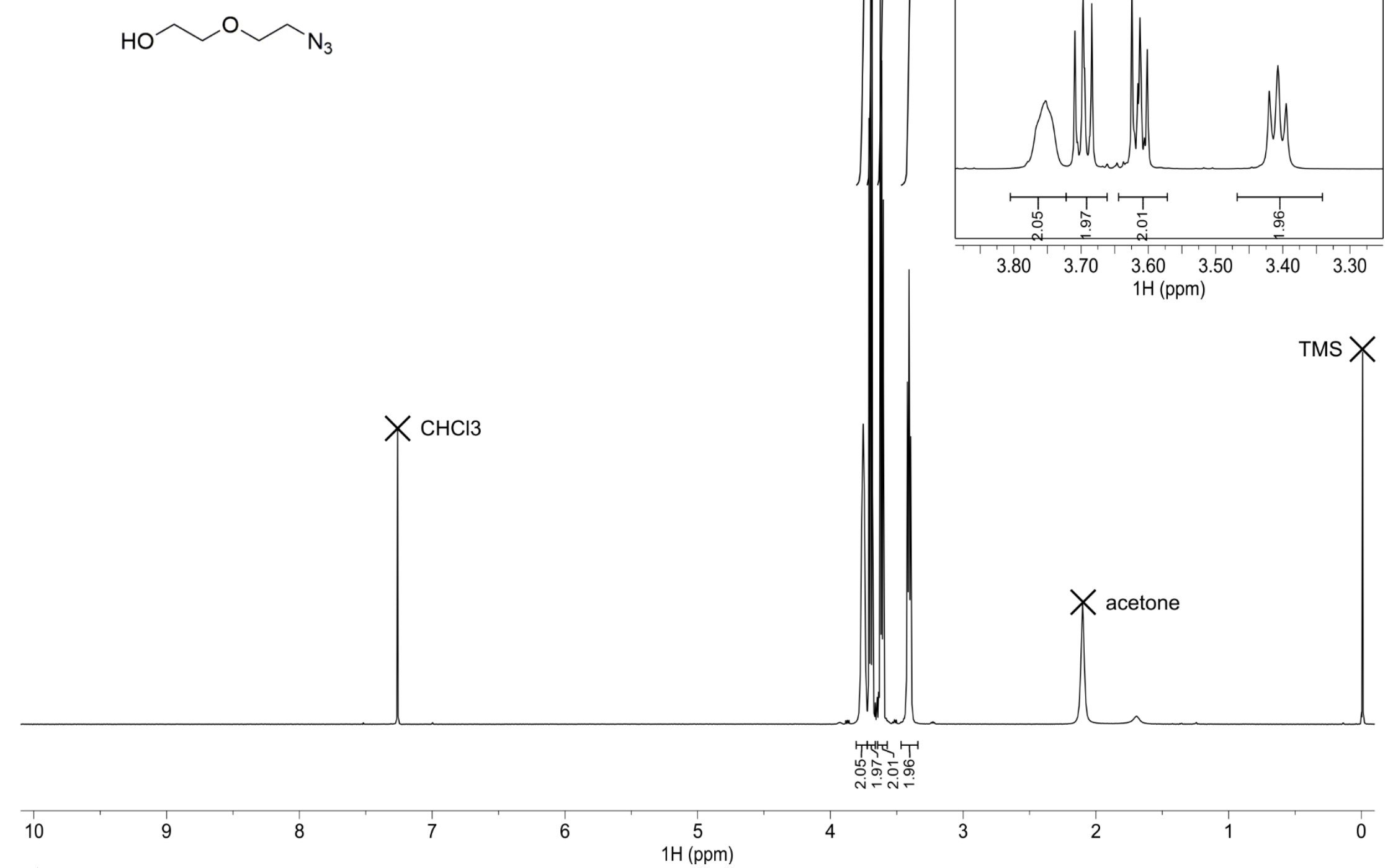

Figure S1. ${ }^{1} \mathrm{H} \mathrm{NMR}\left(\mathrm{CDCl}_{3}, 400 \mathrm{MHz}, 298 \mathrm{~K}\right)$ spectrum of 2. 


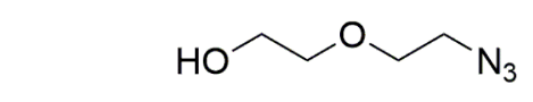

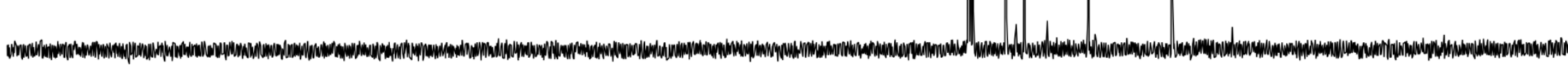

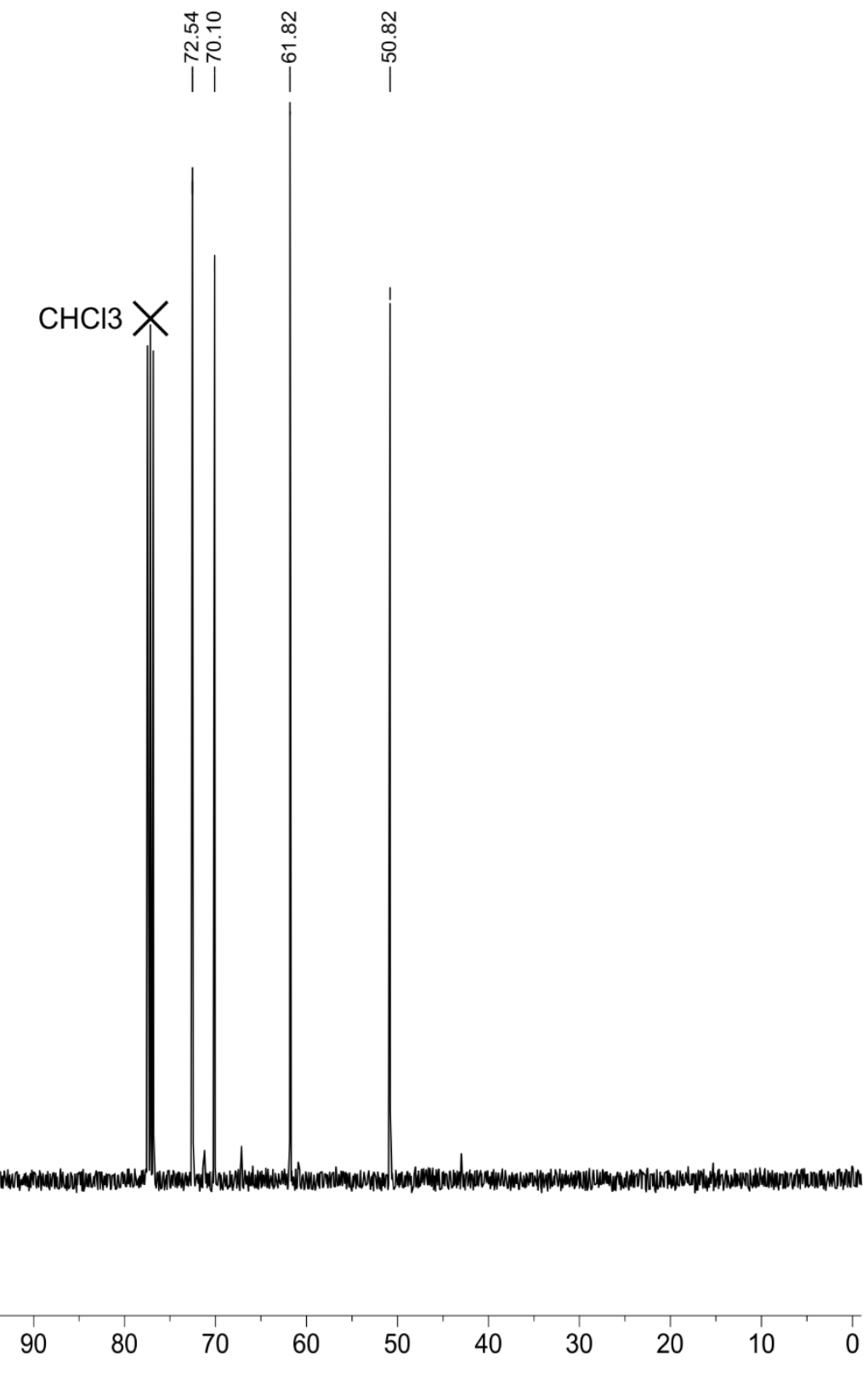

Figure S2. ${ }^{13} \mathrm{C}$ NMR $\left(\mathrm{CDCl}_{3}, 101 \mathrm{MHz}, 298 \mathrm{~K}\right)$ spectrum of 2. 

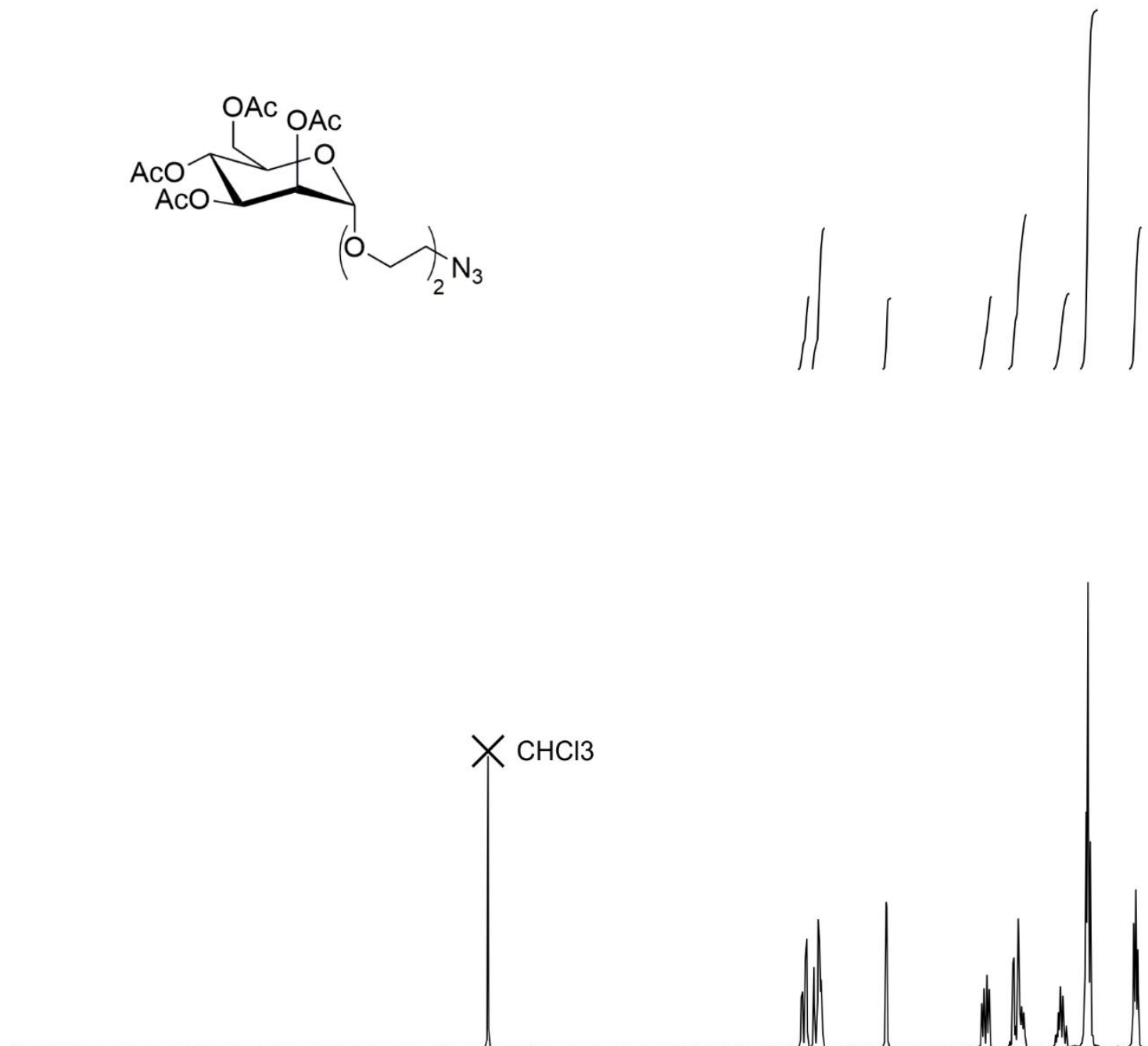

Figure S3. ${ }^{1} \mathrm{H}$ NMR $\left(\mathrm{CDCl}_{3}, 400 \mathrm{MHz}, 298 \mathrm{~K}\right)$ spectrum of Man-4. 

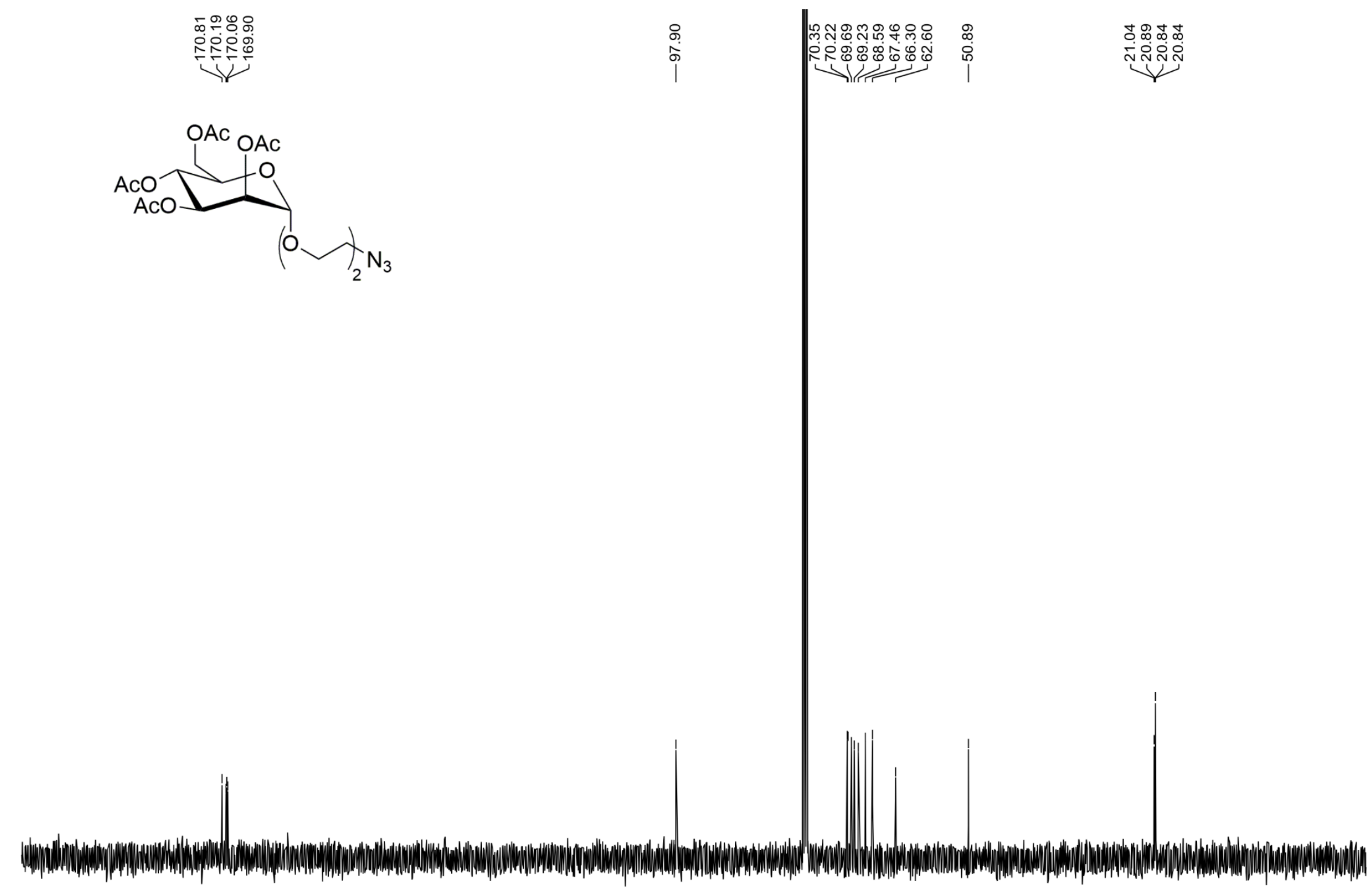

$\begin{array}{lllllllll}200 & 190 & 180 & 170 & 160 & 150 & 140 & 130 & 120\end{array}$ $\begin{array}{rr}100 & 90 \\ 13 \mathrm{C}(\mathrm{ppm})\end{array}$

Figure S4. ${ }^{13} \mathrm{C}$ NMR $\left(\mathrm{CDCl}_{3}, 101 \mathrm{MHz}, 298 \mathrm{~K}\right)$ spectrum of Man-4. 


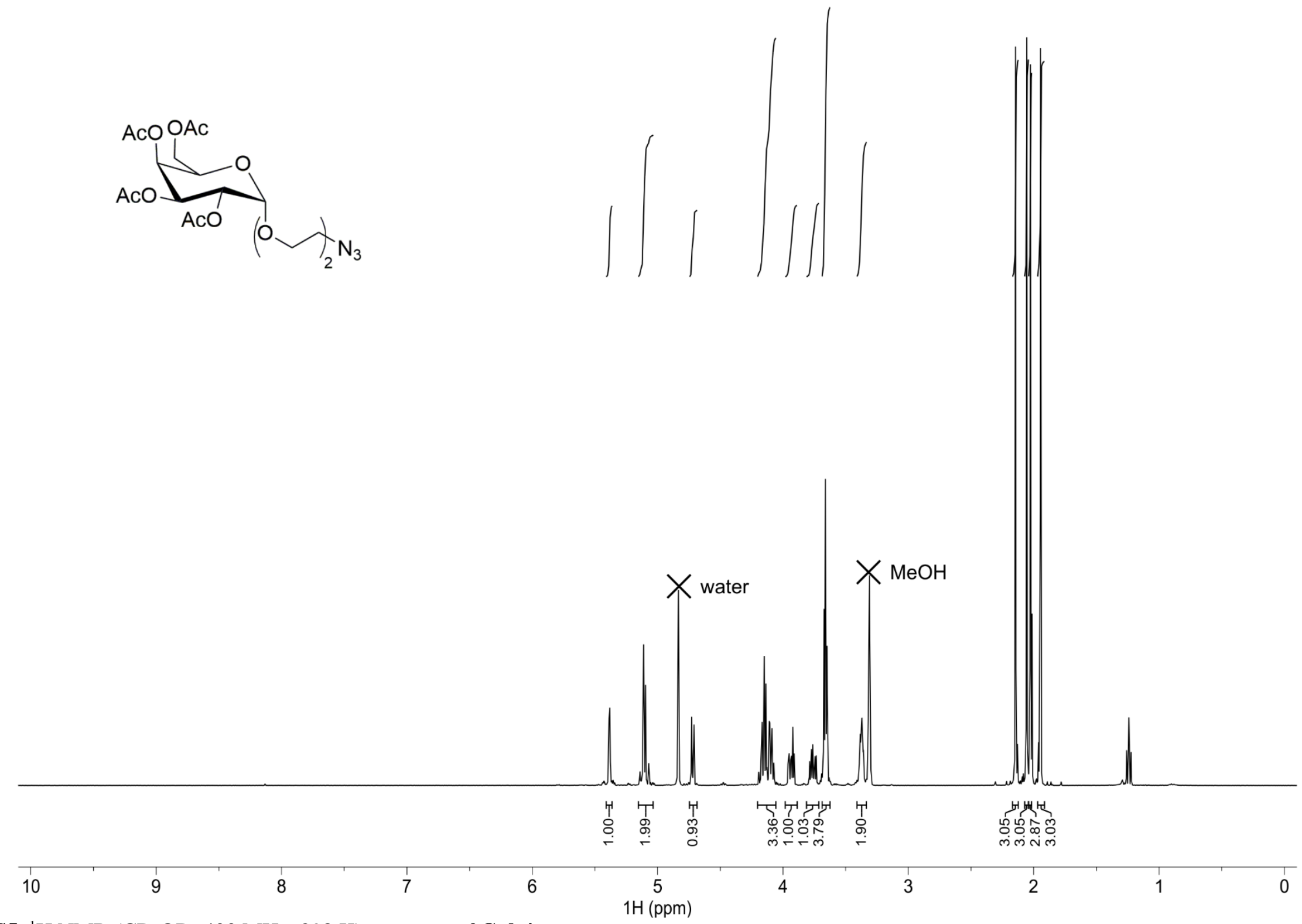

Figure S5. ${ }^{1} \mathrm{H}$ NMR $\left(\mathrm{CD}_{3} \mathrm{OD}, 400 \mathrm{MHz}, 298 \mathrm{~K}\right)$ spectrum of Gal-4. 


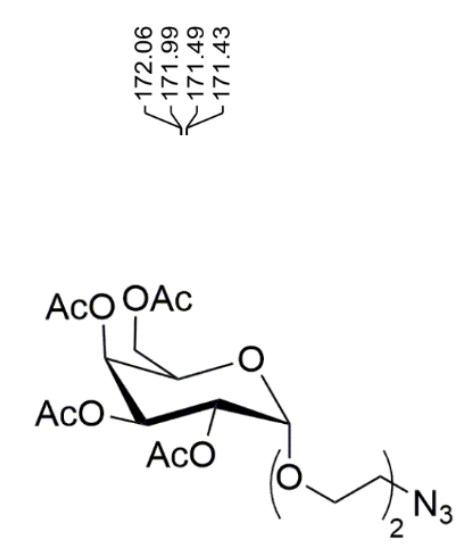

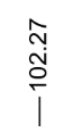

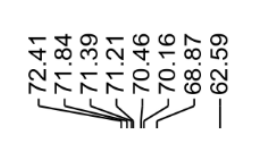

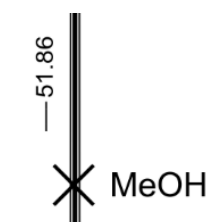

구용ำ

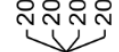

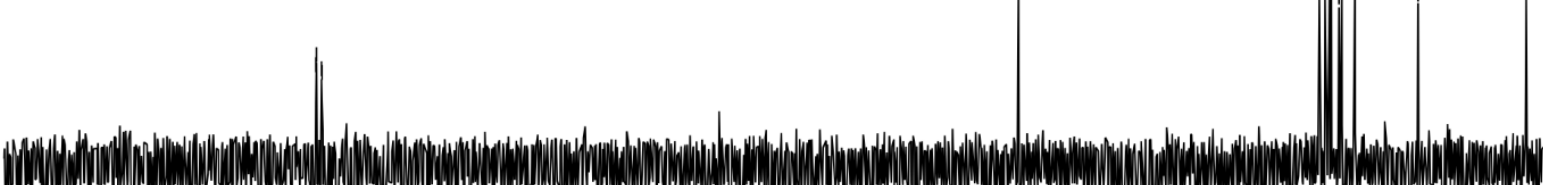

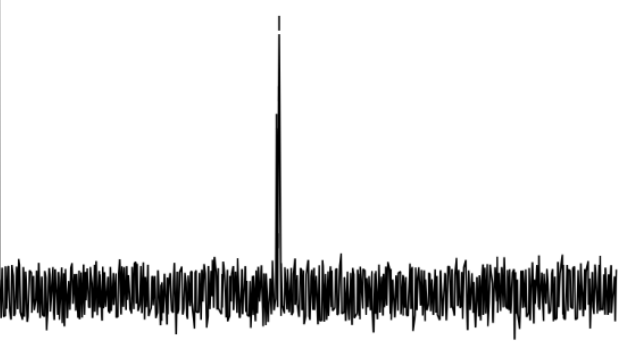

$200 \quad 190 \quad 180 \quad 170 \quad 160 \quad 150$

$140 \quad 130$

$\begin{array}{lr}100 & 90 \\ 13 \mathrm{C}(\mathrm{ppm})\end{array}$

$80 \quad 70$

60

50 $40 \quad 30$

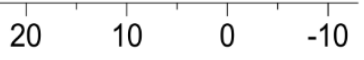

Figure S6. ${ }^{13} \mathrm{C}$ NMR $\left(\mathrm{CD}_{3} \mathrm{OD}, 101 \mathrm{MHz}, 298 \mathrm{~K}\right)$ spectrum of Gal-4. 


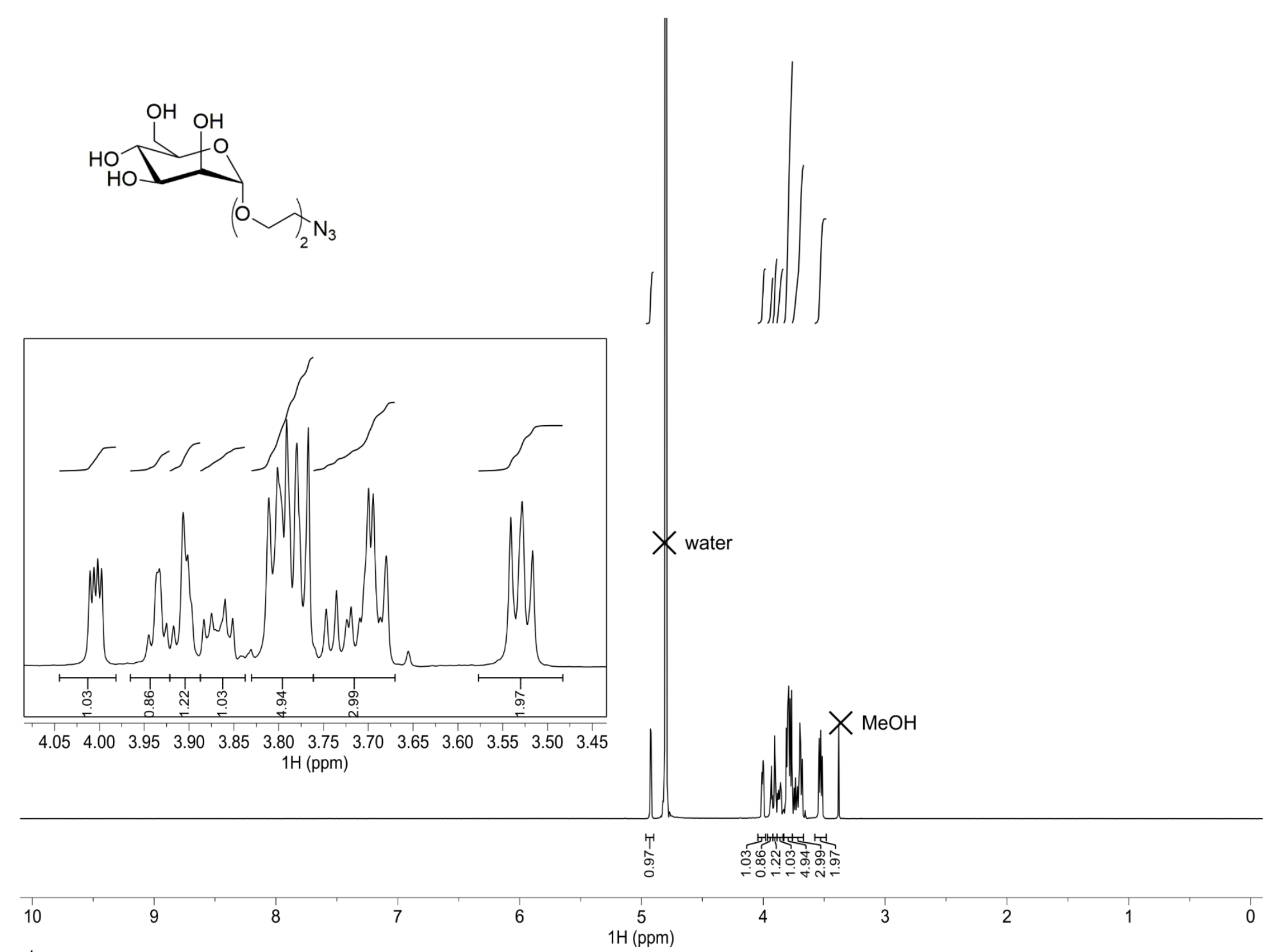

Figure S7. ${ }^{1} \mathrm{H}$ NMR $\left(\mathrm{D}_{2} \mathrm{O}, 400 \mathrm{MHz}, 298 \mathrm{~K}\right)$ spectrum of Man-5. 

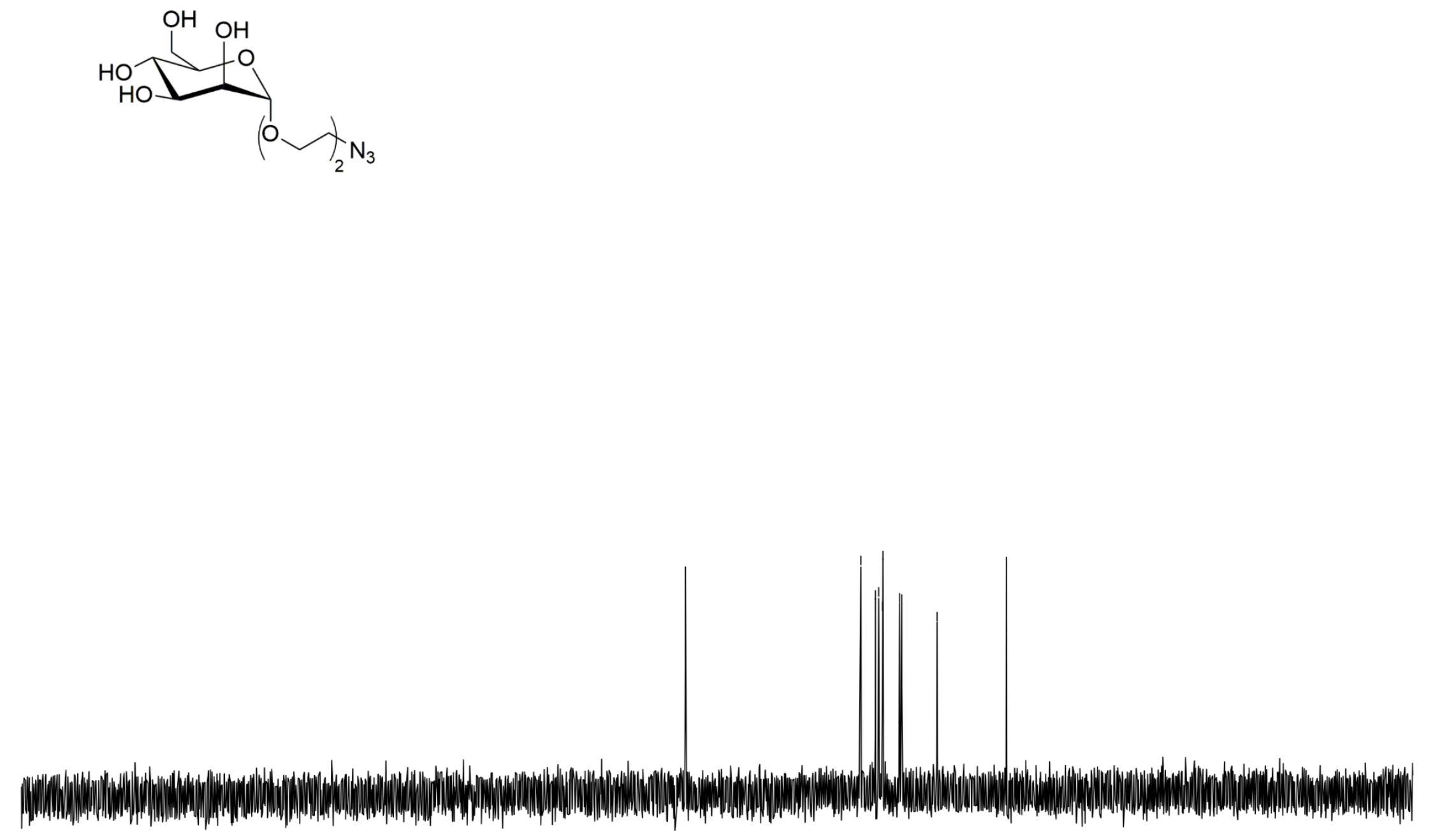

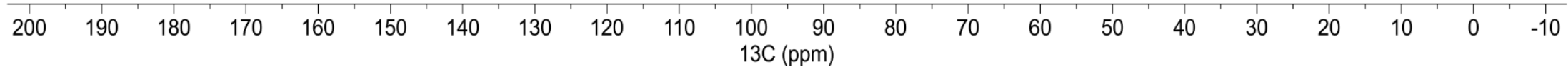

Figure S8. ${ }^{13} \mathrm{C}$ NMR $\left(\mathrm{D}_{2} \mathrm{O}, 101 \mathrm{MHz}, 298 \mathrm{~K}\right)$ spectrum of Man-5. 


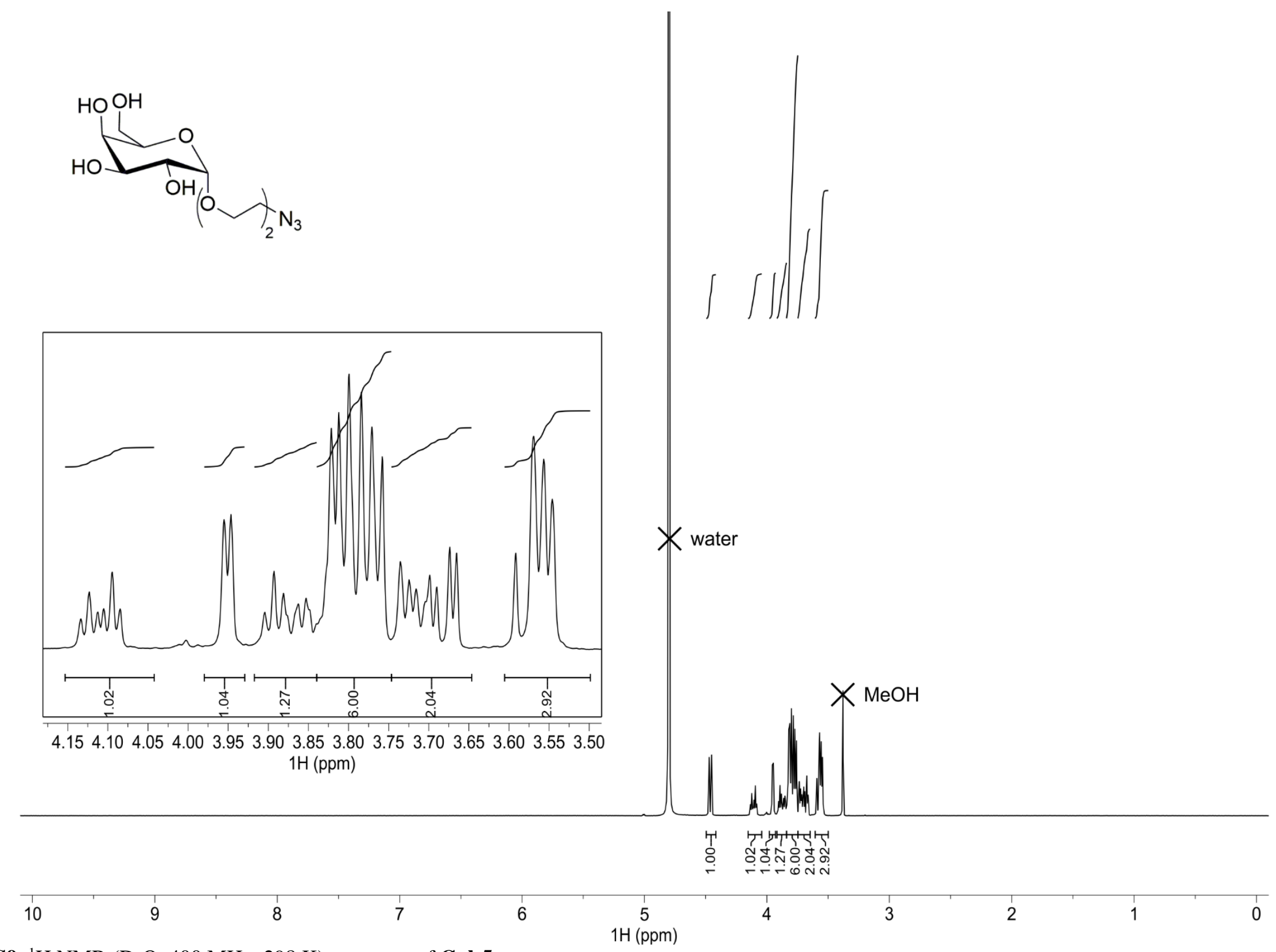

Figure S9. ${ }^{1} \mathrm{H}$ NMR $\left(\mathrm{D}_{2} \mathrm{O}, 400 \mathrm{MHz}, 298 \mathrm{~K}\right)$ spectrum of Gal-5. 

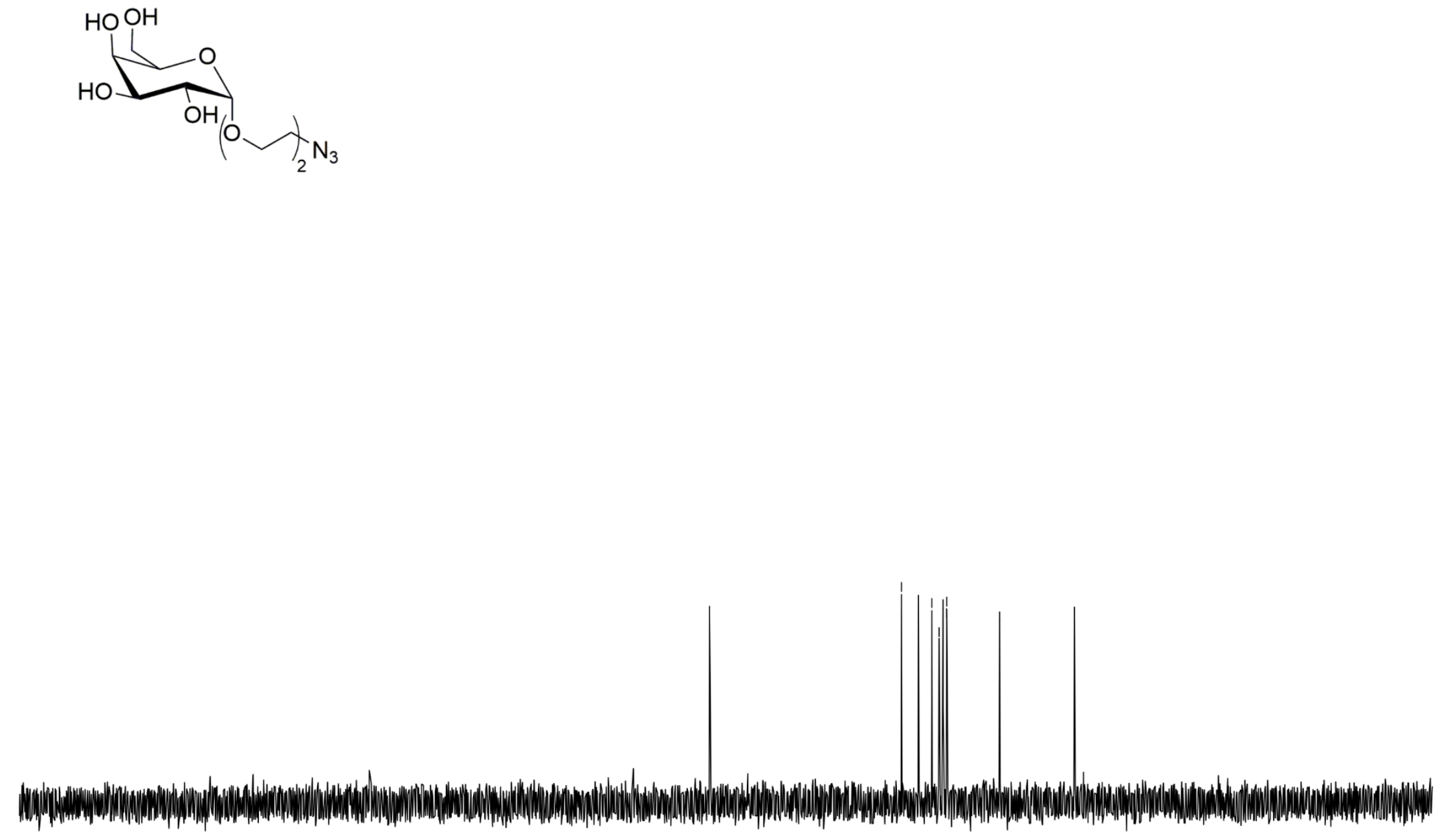

$\begin{array}{llll}200 \quad 190 \quad 180 & 170 \quad 160\end{array}$

$150 \quad 140$

130

$110 \begin{array}{cc}100 & 90\end{array}$

80

$70 \quad 60$

$\begin{array}{llllll}50 & 40 & 30 & 20 & 10 & 0\end{array}$

Figure S10. ${ }^{13} \mathrm{C}$ NMR $\left(\mathrm{D}_{2} \mathrm{O}, 101 \mathrm{MHz}, 298 \mathrm{~K}\right)$ spectrum of Gal-5. 


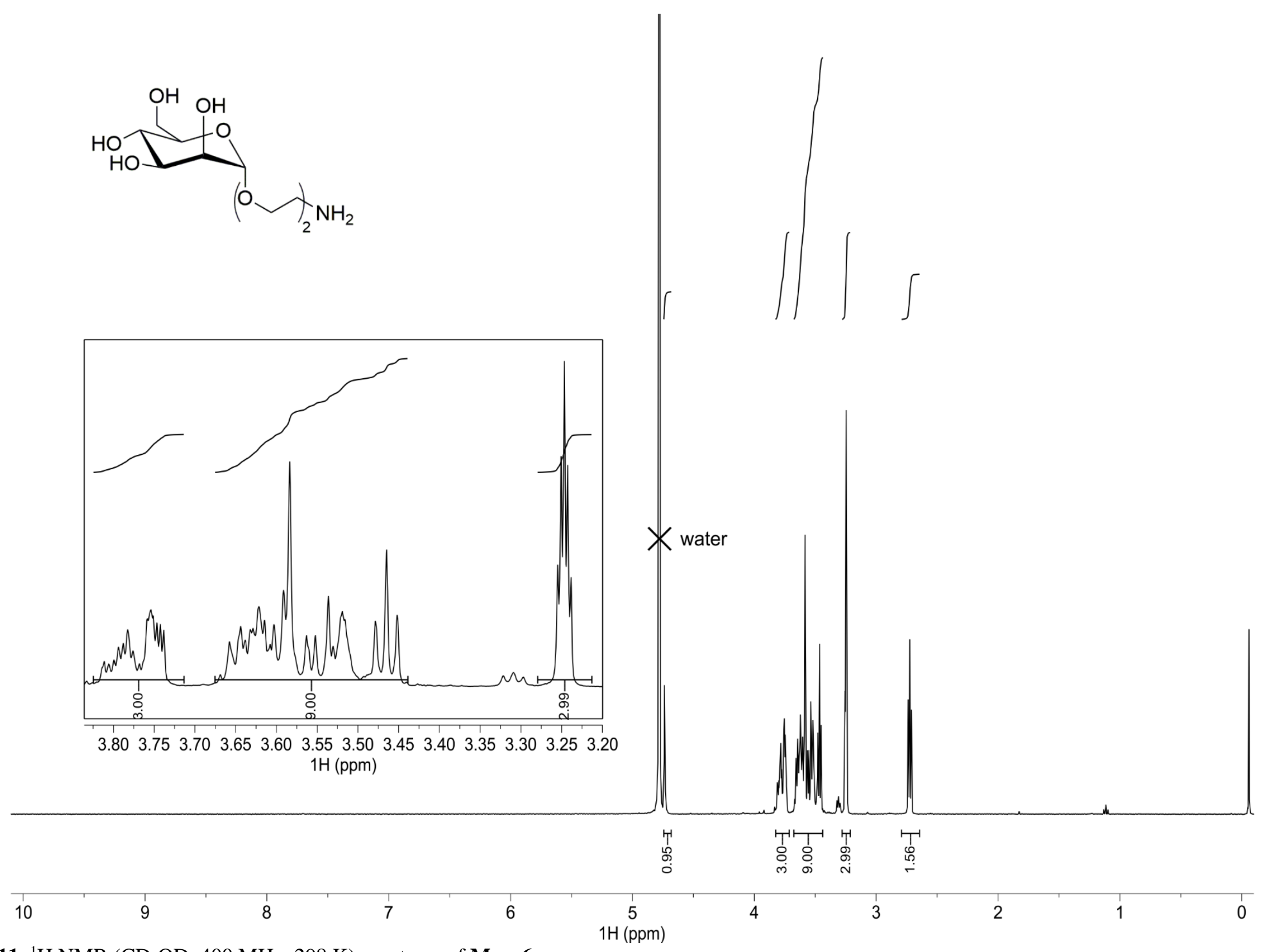

Figure S11. ${ }^{1} \mathrm{H}$ NMR $\left(\mathrm{CD}_{3} \mathrm{OD}, 400 \mathrm{MHz}, 298 \mathrm{~K}\right)$ spectrum of Man-6. 


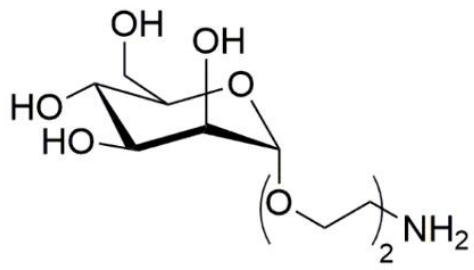

|

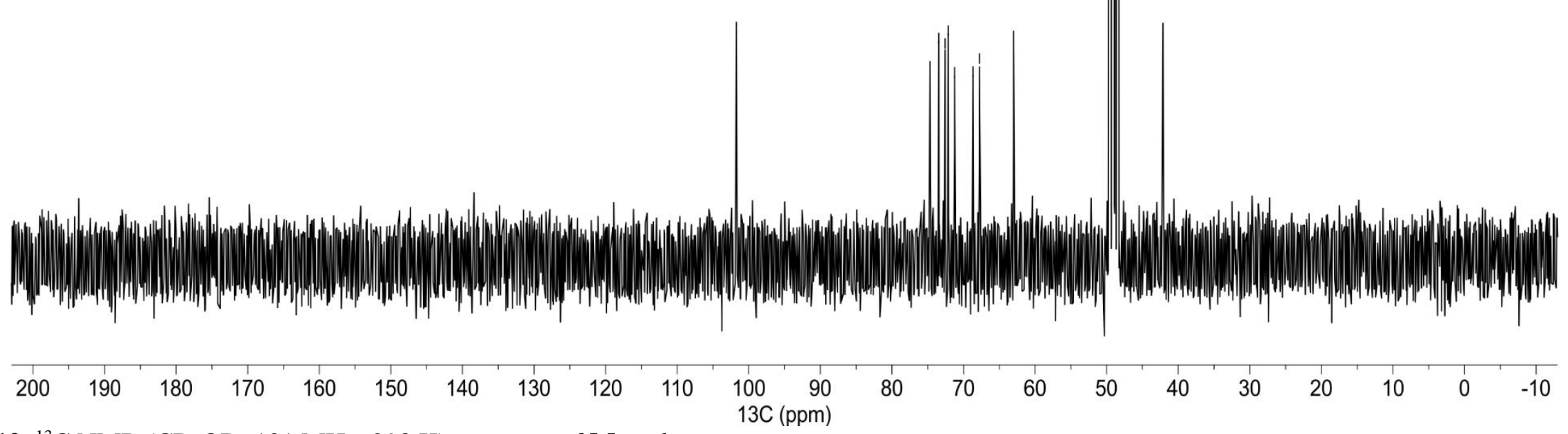

Figure S12. ${ }^{13} \mathrm{C}$ NMR $\left(\mathrm{CD}_{3} \mathrm{OD}, 101 \mathrm{MHz}, 298 \mathrm{~K}\right)$ spectrum of Man-6. 

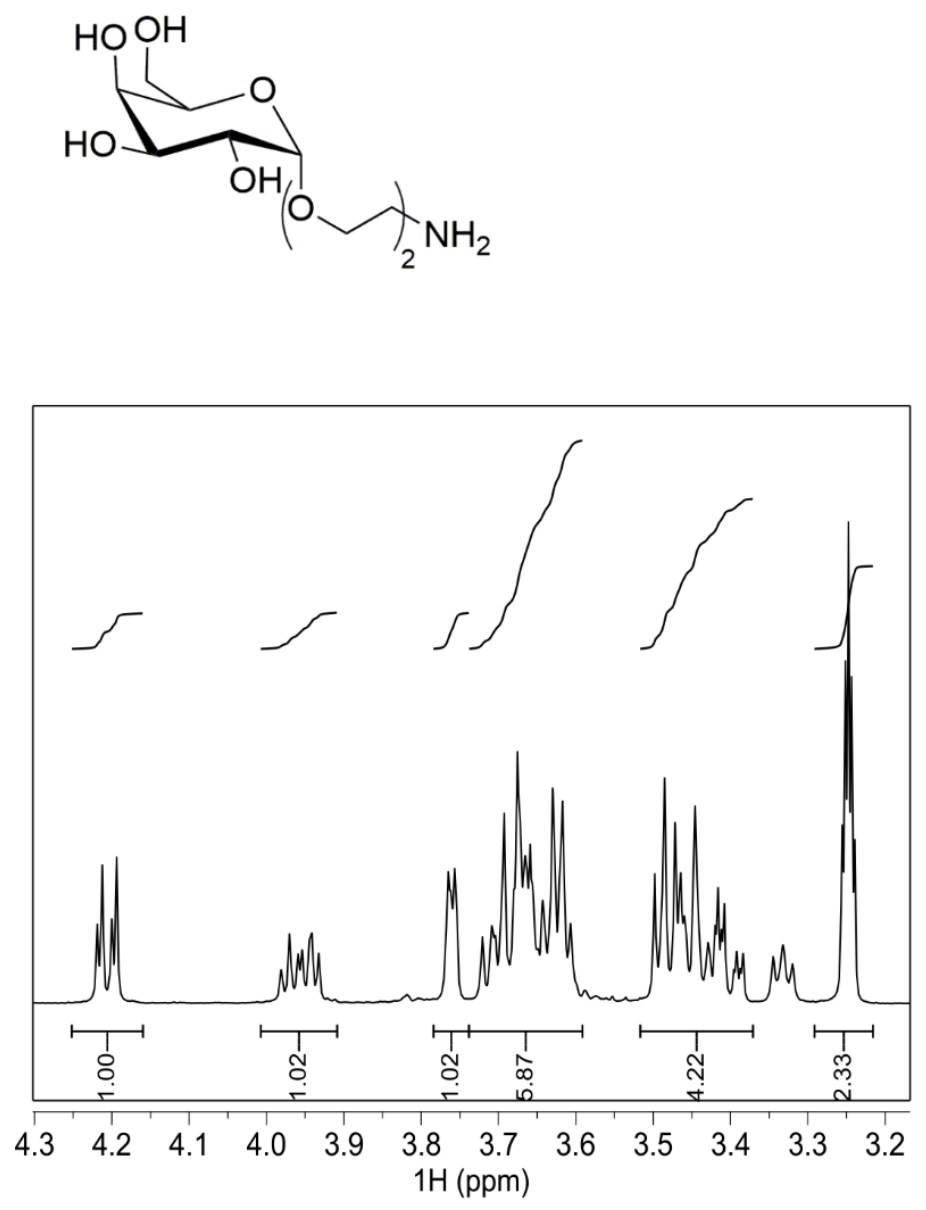

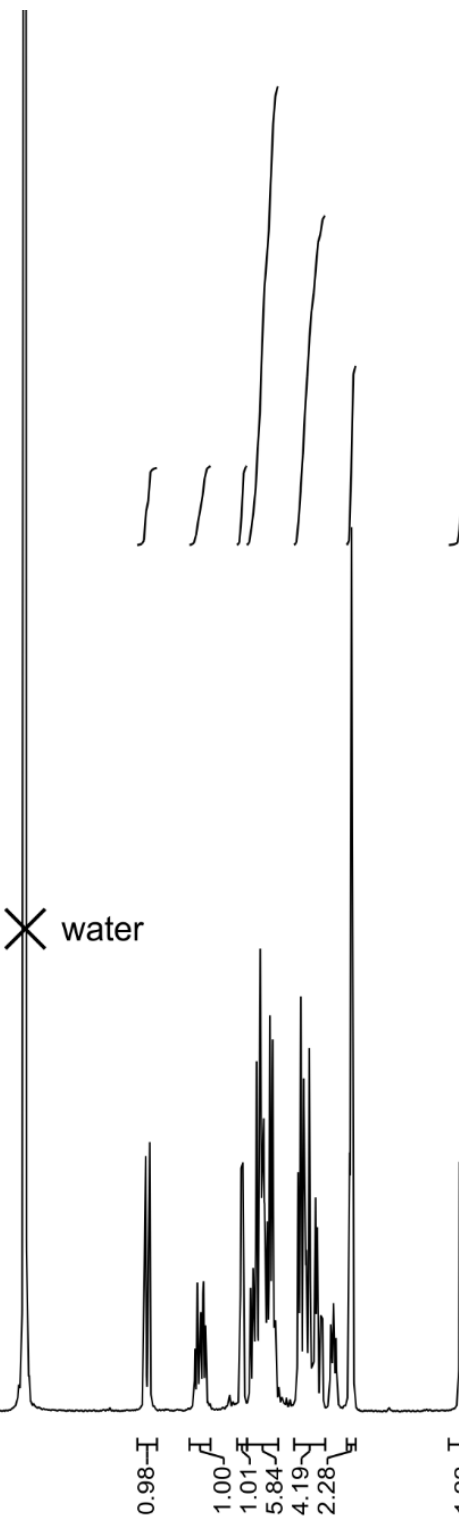
4 $1 \mathrm{H}(\mathrm{ppm})$

Figure S13. ${ }^{1} \mathrm{H} \mathrm{NMR}\left(\mathrm{CD}_{3} \mathrm{OD}, 400 \mathrm{MHz}, 298 \mathrm{~K}\right)$ spectrum of Gal-6. 


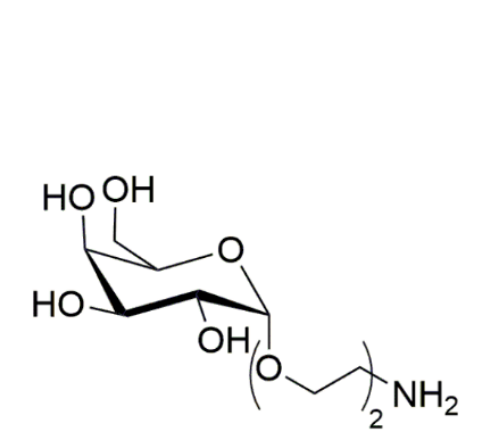

|

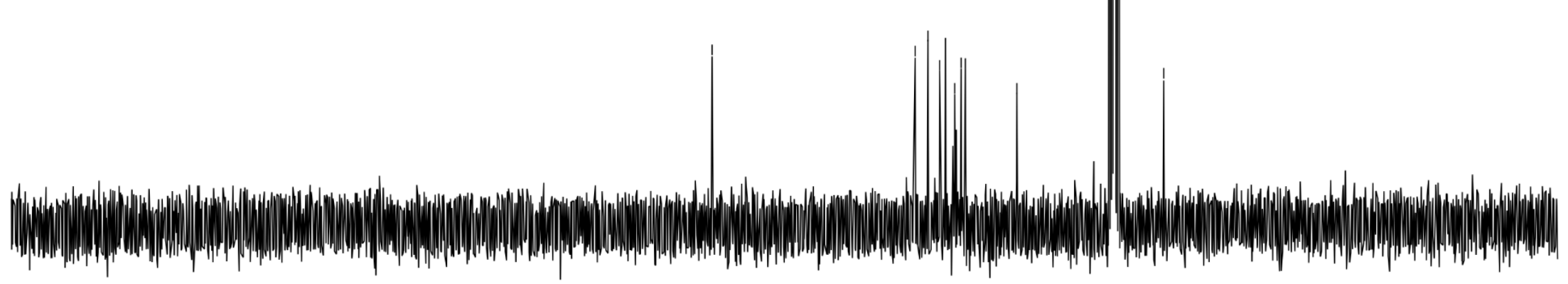

$\begin{array}{llllllll}200 & 190 & 180 & 170 & 160 & 150 & 140 & 130\end{array}$

$120 \quad 110$ $\begin{array}{lr}100 & 90 \\ 13 \mathrm{C}(\mathrm{ppm})\end{array}$

Figure S14. ${ }^{13} \mathrm{C}$ NMR $\left(\mathrm{CD}_{3} \mathrm{OD}, 101 \mathrm{MHz}, 298 \mathrm{~K}\right)$ spectrum of Gal-6. 

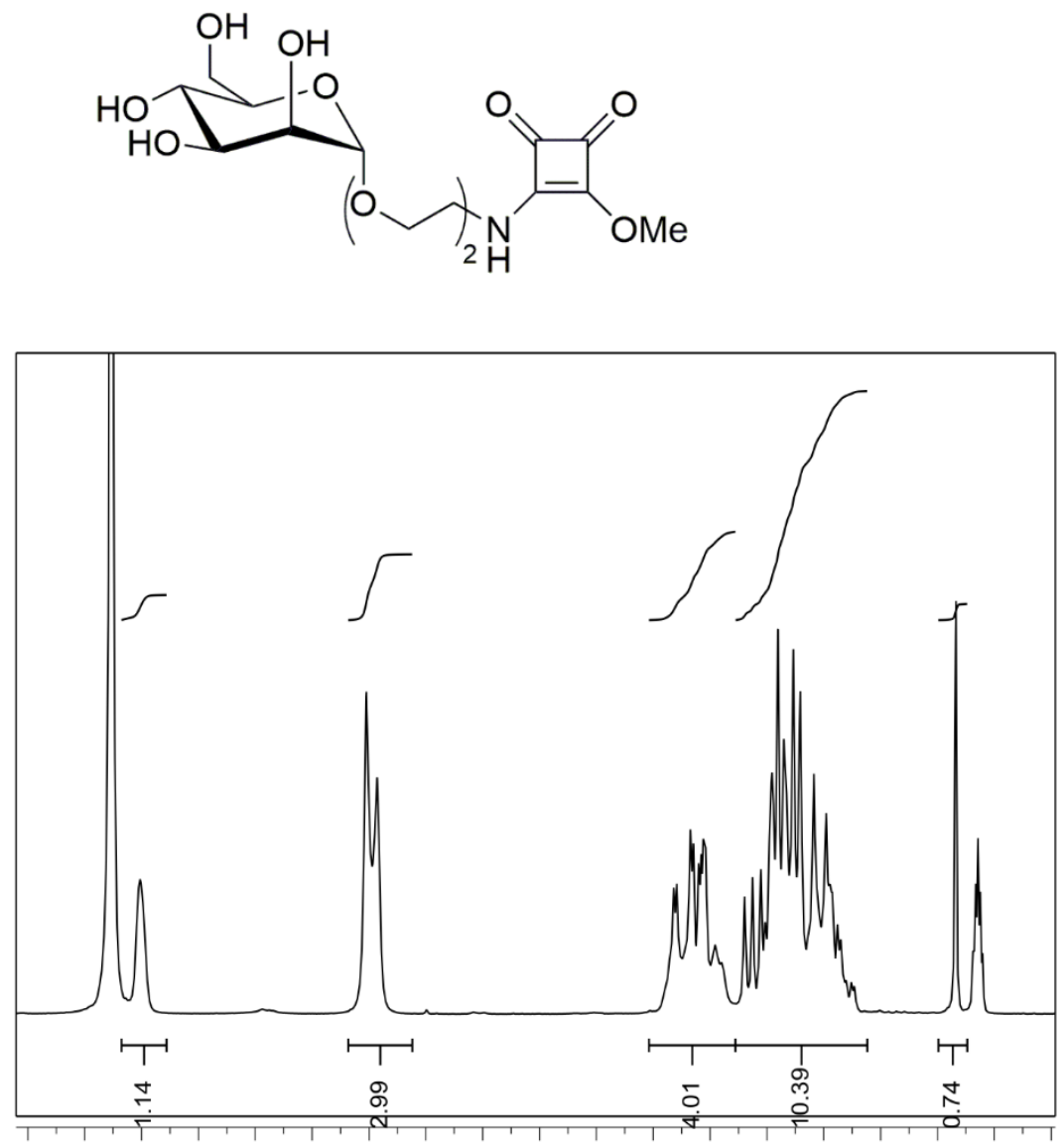

$\begin{array}{lllllllllllllllllll}5.0 & 4.9 & 4.8 & 4.7 & 4.6 & 4.5 & 4.4 & 4.3 & 4.2 & 4.1 & 4.0 & 3.9 & 3.8 & 3.7 & 3.6 & 3.5 & 3.4 & 3.3 & 3.2\end{array}$ $1 \mathrm{H}(\mathrm{ppm})$

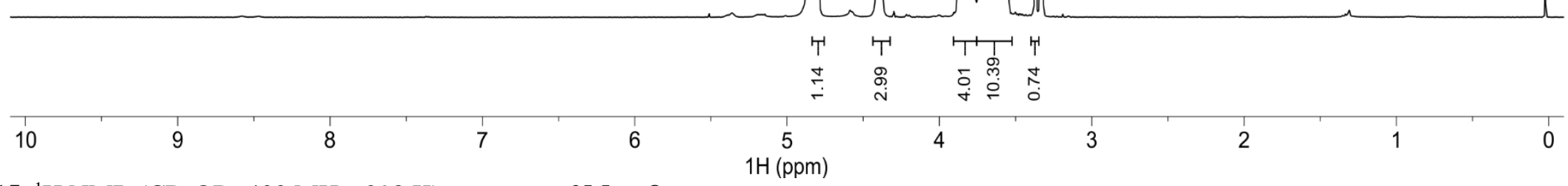

Figure S15. ${ }^{1} \mathrm{H}$ NMR $\left(\mathrm{CD}_{3} \mathrm{OD}, 400 \mathrm{MHz}, 298 \mathrm{~K}\right)$ spectrum of Man-8. 


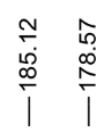
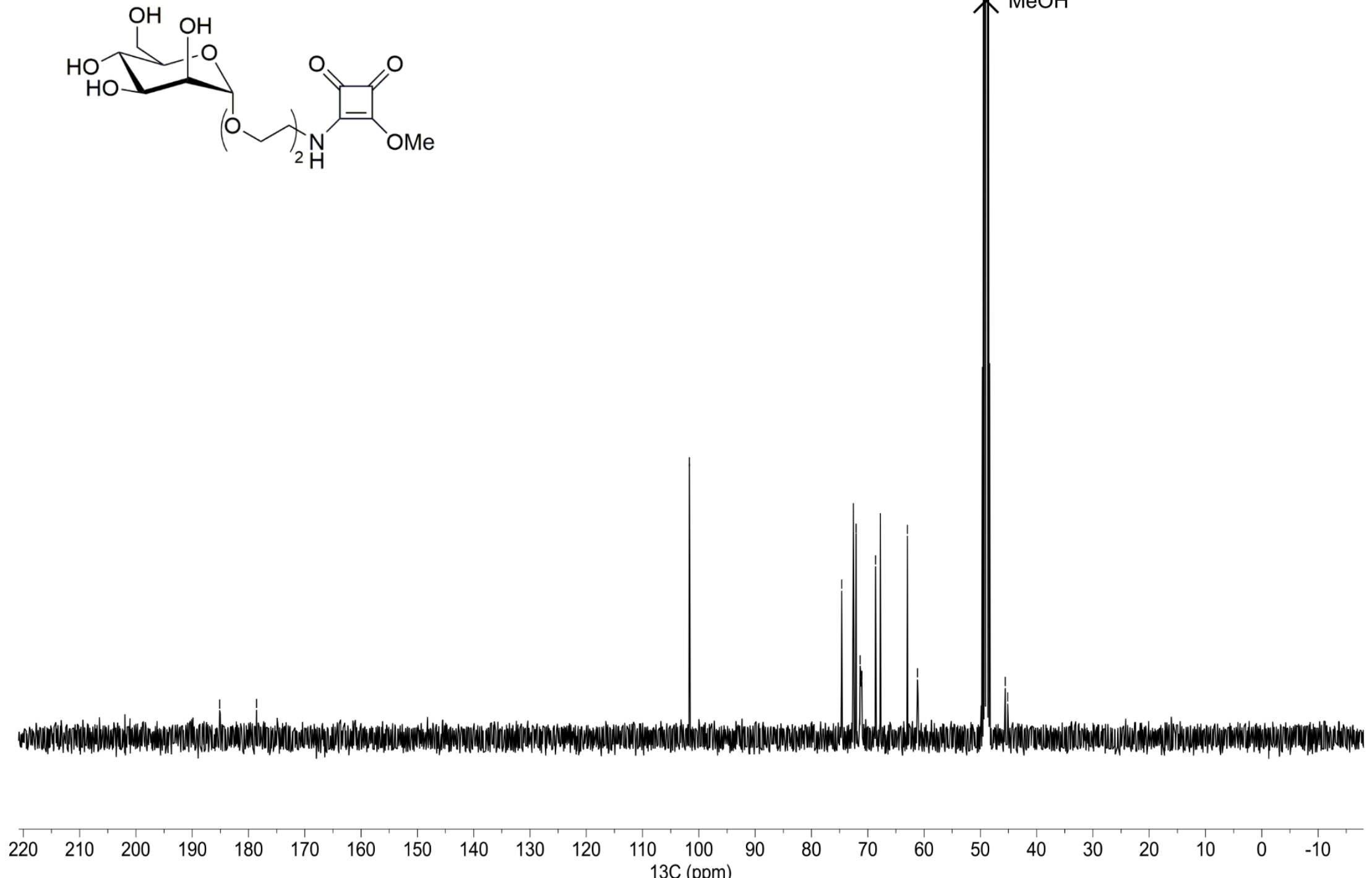
$110 \quad 100$
$13 \mathrm{C}(\mathrm{ppm})$

Figure S16. ${ }^{13} \mathrm{C}$ NMR $\left(\mathrm{CD}_{3} \mathrm{OD}, 101 \mathrm{MHz}, 298 \mathrm{~K}\right)$ spectrum of Man-8 

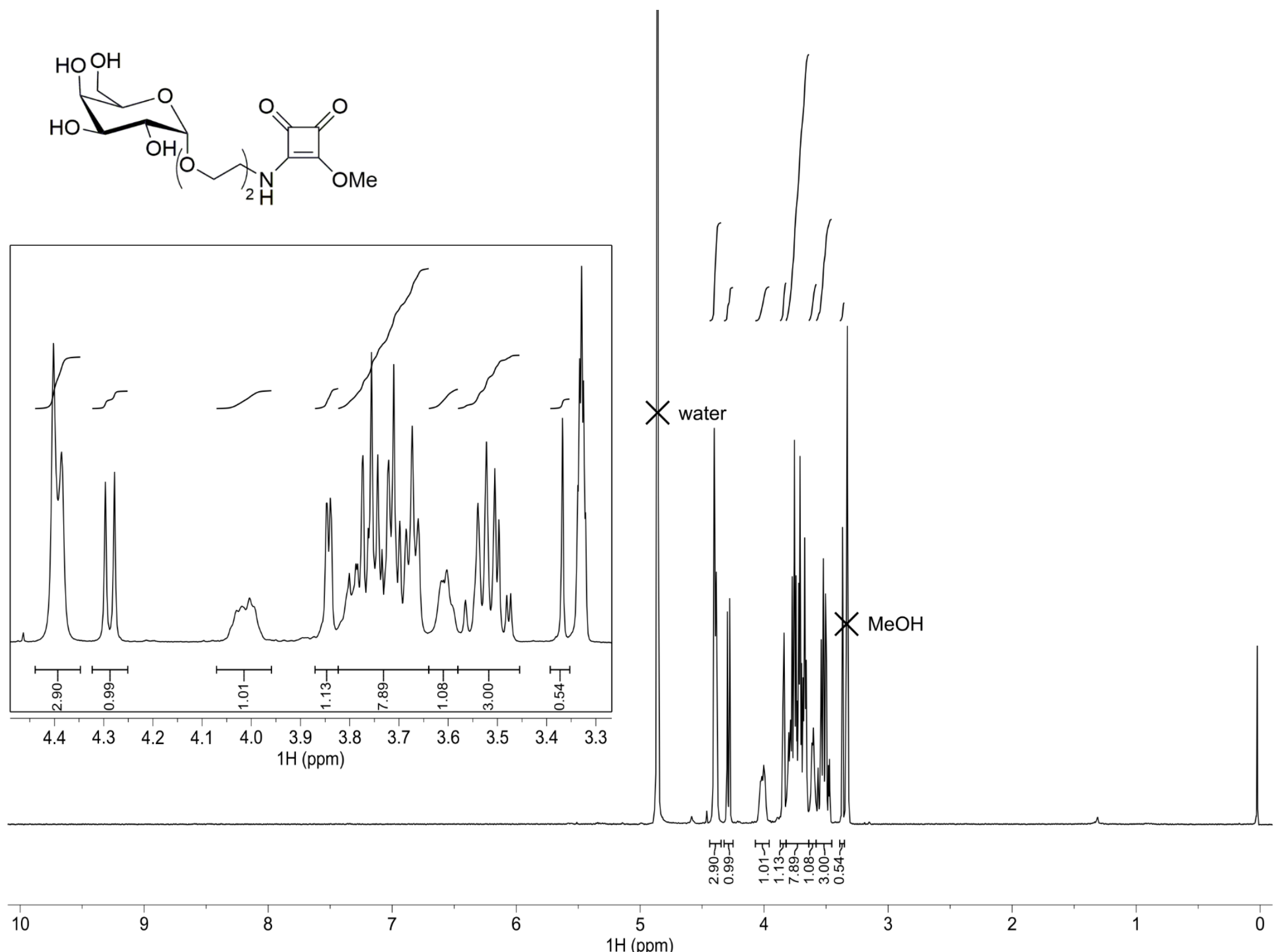

Figure S17. ${ }^{1} \mathrm{H}$ NMR $\left(\mathrm{CD}_{3} \mathrm{OD}, 400 \mathrm{MHz}, 298 \mathrm{~K}\right)$ spectrum of Gal-8. 
$\overbrace{\substack{\infty \\ 0}}^{\substack{\infty \\ \stackrel{2}{\sigma}}}$

[1

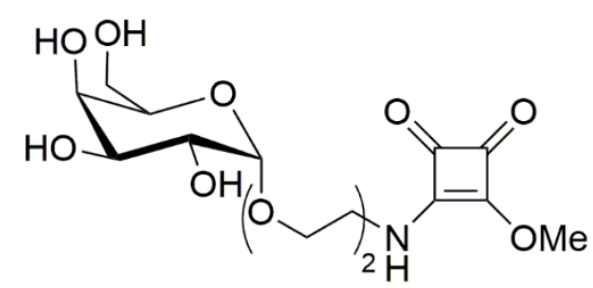

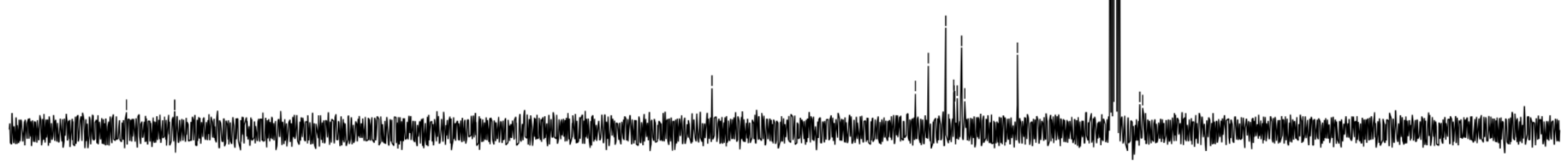

$\begin{array}{llllllllllll}200 & 190 & 180 & 170 & 160 & 150 & 140 & 130 & 120 & 110 & 100 & 90\end{array}$ $13 \mathrm{C}(\mathrm{ppm})$

Figure S18. ${ }^{13} \mathrm{C}$ NMR $\left(\mathrm{CD}_{3} \mathrm{OD}, 101 \mathrm{MHz}, 298 \mathrm{~K}\right)$ spectrum of Gal-8. 


\section{Synthesis and Characterization of DNA Glycoconjugates}

\subsection{Materials and Methods}

Materials. All materials for oligonucleotide synthesis and conjugation were obtained from Glen Research or Fisher, unless otherwise specified, and were used as received.

High performance liquid chromatography (HPLC). Oligonucleotides were purified using reverse-phase HPLC on an Agilent 1260 Infinity II LC system using an Agilent Dynamax Microsorb C18 column, eluting with a gradient of acetonitrile in triethylammonium acetate buffer that varied depending on the oligonucleotide design.

Mass spectrometry. The identities of purified oligonucleotides were confirmed by matrix-assisted laser-desorption ionization time-of-flight mass spectrometry (MALDI-TOF MS) using a Bruker MALDI Rapiflex Tissue Typer instrument in linear mode with negative ion detection using $2^{\prime}, 6^{\prime}$-dihydroxyacetophenone as matrix and diammonium hydrogen citrate as co-matrix. All observed masses were within $10 \mathrm{Da}$ of the calculated mass.

\subsection{Synthesis of Amine-Functionalized Oligonucleotides}

Oligonucleotides (9) and their respective glycoconjugates (10) used in this study are listed in Table S1. Oligonucleotides were synthesized on a Bio Automation MerMade 12 oligonucleotide synthesizer using standard conditions on solid controlled pore glass (CPG) beads, on a $5 \mu \mathrm{mol}$ scale, with acetonitrilic 4,5-dicyanoimidazole solution as activator and iodine solution as oxidizer. Amine moieties were incorporated at terminal or internal positions using either 5'-amino-modifier C6 or amino-modifier C2 dT phosphoramidite (Glen Research \#10-1906 and \#10-1037, respectively; Scheme S2).

\section{Scheme S2. Structures of Phosphoramidites with Amine Functional Groups}
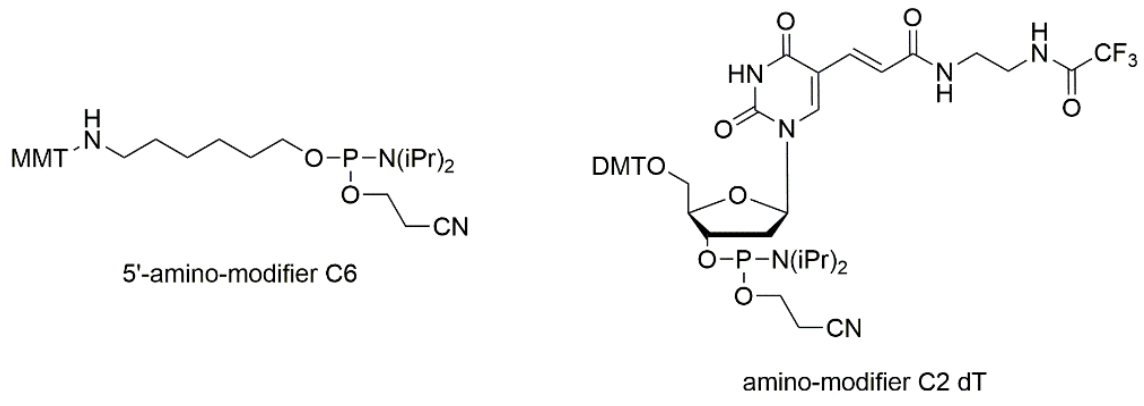

Oligonucleotides were cleaved from CPG using standard AMA protection. Specifically, CPG beads containing $5 \mu \mathrm{mol}$ of oligonucleotides were suspended in $3 \mathrm{~mL}$ of a 1:1 mixture of $30 \% \mathrm{NH}_{3}$ (aq) and $40 \%$ methylamine (aq) (3 $\mathrm{mL}$ ) for $40 \mathrm{~min}$ at $55^{\circ} \mathrm{C}$. After cooling to $\mathrm{rt}$, Tris buffer $(1 \mathrm{M}, \mathrm{pH} 8,300 \mu \mathrm{L})$ was added to prevent premature cleavage of the MMT protecting groups. Volatile amines were removed under a stream of $\mathrm{N}_{2}$ (Organomation Multivap) and CPG was removed by filtration through a $0.2 \mu \mathrm{m}$ filter (Amicon). The residue was purifed using reverse-phase HPLC (see method in SI Section 2.1). Extinction coefficients $\left(\varepsilon_{260}\right)$ listed in Table S1 were used to 
determine oligonucleotide concentration based on their absorbance at $260 \mathrm{~nm}$ (Cary 5000 UV-vis spectrophotometer). Molecular weights (MW) were determined by MALDI-TOF MS.

Table S1. Sequences, Extinction Coefficients, and Calculated and Observed Molecular Weights of Oligonucleotides (9) and DNA Glycoconjugates (10)

\begin{tabular}{|c|c|c|c|c|c|c|c|}
\hline \multicolumn{4}{|c|}{ Oligonucleotide (9) } & \multicolumn{4}{|c|}{ DNA glycoconjugate (10) } \\
\hline \multirow{2}{*}{ Sequence $\left(5^{\prime} \text { to } 3^{\prime}\right)^{a}$} & \multirow{2}{*}{$\begin{array}{c}\mathbf{\varepsilon} 260 \\
\left(\mathbf{M}^{-\mathbf{1}} \mathbf{c m}^{-\mathbf{1}}\right)^{b}\end{array}$} & \multicolumn{2}{|c|}{ MW (Da) } & \multirow{2}{*}{ Sequence $\left(5^{\prime} \text { to } 3^{\prime}\right)^{c}$} & \multirow{2}{*}{$\begin{array}{c}\mathbf{\varepsilon} 260 \\
\left(\mathbf{M}^{-1} \mathbf{c m}^{-1}\right)^{d}\end{array}$} & \multicolumn{2}{|c|}{ MW (Da) } \\
\hline & & Calcd & Found & & & Calcd & Found \\
\hline \multirow{2}{*}{$\left(5^{\prime}-\mathrm{NH}_{2}\right)-\mathrm{ATAT}$} & \multirow{2}{*}{44900} & \multirow{2}{*}{1352} & \multirow{2}{*}{1344} & Man-ATAT & 55700 & 1698 & 1695 \\
\hline & & & & Gal-ATAT & 55700 & 1698 & 1698 \\
\hline$\left(5^{\prime}-\mathrm{NH}_{2}\right)-\mathrm{AGCT}$ & 38900 & 1353 & 1346 & Man-AGCT & 49700 & 1699 & 1696 \\
\hline$\left(5^{\prime}-\mathrm{NH}_{2}\right)-\mathrm{GTAC}$ & 40500 & 1353 & 1352 & Man-GTAC & 51300 & 1699 & 1694 \\
\hline$\left(5^{\prime}-\mathrm{NH}_{2}\right)-\mathrm{CGCG}$ & 34700 & 1354 & 1352 & Man-CGCG & 45500 & 1699 & 1689 \\
\hline$\left(5^{\prime}-\mathrm{NH}_{2}\right)-\mathrm{AAAA}$ & 51400 & 1370 & 1368 & Man-AAAA & 62200 & 1716 & 1712 \\
\hline$\left(5^{\prime}-\mathrm{NH}_{2}\right)-\mathrm{TTTT}$ & 33000 & 1334 & 1331 & Man-TTTT & 43800 & 1680 & 1677 \\
\hline$\left(5^{\prime}-\mathrm{NH}_{2}\right)-\mathrm{AAATTT}$ & 63000 & 1969 & 1968 & Man-AAATTT & 73800 & 2314 & 2313 \\
\hline$\left(5^{\prime}-\mathrm{NH}_{2}\right)-$ AAAATTTT & 83100 & 2587 & 2586 & Man-AAAATTTT & 93900 & 2932 & 2931 \\
\hline $\mathrm{A}\left(\mathrm{NH}_{2}-\mathrm{T}\right) \mathrm{AT}$ & 44900 & 1271 & 1268 & A(Man-T)AT & 55700 & 1617 & 1614 \\
\hline $\mathrm{G}\left(\mathrm{NH}_{2}-\mathrm{T}\right) \mathrm{AC}$ & 40500 & 1272 & 1270 & $\mathrm{G}(\mathrm{Man}-\mathrm{T}) \mathrm{AC}$ & 51300 & 1618 & 1615 \\
\hline $\mathrm{T}\left(\mathrm{NH}_{2}-\mathrm{T}\right) \mathrm{TT}$ & 33000 & 1253 & 1252 & $\mathrm{~T}($ Man-T)TT & 43800 & 1599 & 1595 \\
\hline
\end{tabular}

${ }^{a}\left(5^{\prime}-\mathrm{NH}_{2}\right)$ denotes 5'-amino-modifier C6 phosphoramidite (Glen Research \#10-1906); $\left(\mathrm{NH}_{2}-\mathrm{T}\right)$ denotes amino-modifier C2 dT phosphoramidite (Glen Research \#10-1037). ${ }^{b}$ Values of $\varepsilon_{260}$ were calculated using the IDT Oligo Analyzer tool. ${ }^{7} \mathrm{Man}$ and Gal denote glycoconjugates prepared from respective oligonucleotide (9) and either Man-8 or Gal-8, respectively. ${ }^{d}$ Values of $\varepsilon_{260}$ were calculated from $\varepsilon_{260}$ for the respective oligonucleotide (9) by adding $\varepsilon_{260}$ for Man-8, which was empirically determined to be $10800 \mathrm{M}^{-1} \mathrm{~cm}^{-1}$ (see SI section 2.4). 


\subsection{Conjugation of Sugar-Squaramides to Oligonucleotides}

Glycoconjugation reactions were typically performed on the $1 \mu \mathrm{mol}$ scale with respect to DNA (9, Scheme S3). For a $1 \mu \mathrm{mol}$ reaction, to a $1.5 \mathrm{~mL}$ Eppendorf tube were added:

- $200 \mu \mathrm{L}$ of DNA (9) solution in pH 9 sodium borate buffer ( $5 \mathrm{mM}, 1 \mu \mathrm{mol}, 1$ equiv);

- $100 \mu \mathrm{L}$ of Man-8 solution in pH 9 sodium borate buffer (100 mM, $10 \mu \mathrm{mol}, 10$ equiv); and

- $10 \mu \mathrm{L}$ of $\mathrm{NaOH}$ solution in water $(2 \mathrm{M}, 5 \% \mathrm{v} / \mathrm{v}$ with respect to DNA solution).

\section{Scheme S3. Synthesis of DNA Glycoconjugates}

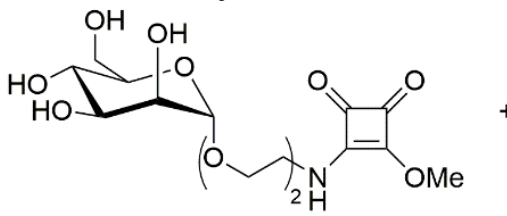

Man-8

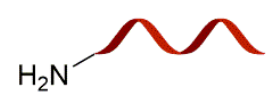

DNA (9)

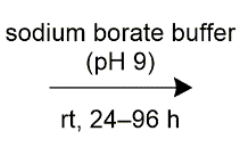

rt, 24-96 h

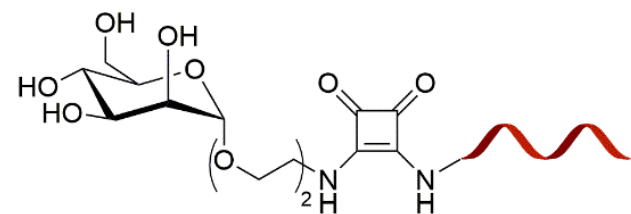

Man-DNA (10)

(0.5-2 umol, $40-75 \%)$

The solution was shaken at $700 \mathrm{rpm}$ at $25^{\circ} \mathrm{C}$ and the reaction progress monitored every $24 \mathrm{~h}$ by MALDI-TOF MS (Figure S19). When the reaction was complete, or no further conversion was observed, the reaction mixture was filtered through a $0.2 \mu \mathrm{m}$ spin filter (Corning Costar Spin-X, $5000 \times g$, rt, $2 \mathrm{~min}$ ) and purified using reverse-phase HPLC (see method in SI Section 2.1). Extinction coefficients $\left(\varepsilon_{260}\right)$ listed in Table S1 were used to determine oligonucleotide concentration based on their absorbance at $260 \mathrm{~nm}$. MWs were determined by MALDI-TOF MS. Samples were lyophilized and stored at $-20^{\circ} \mathrm{C}$.
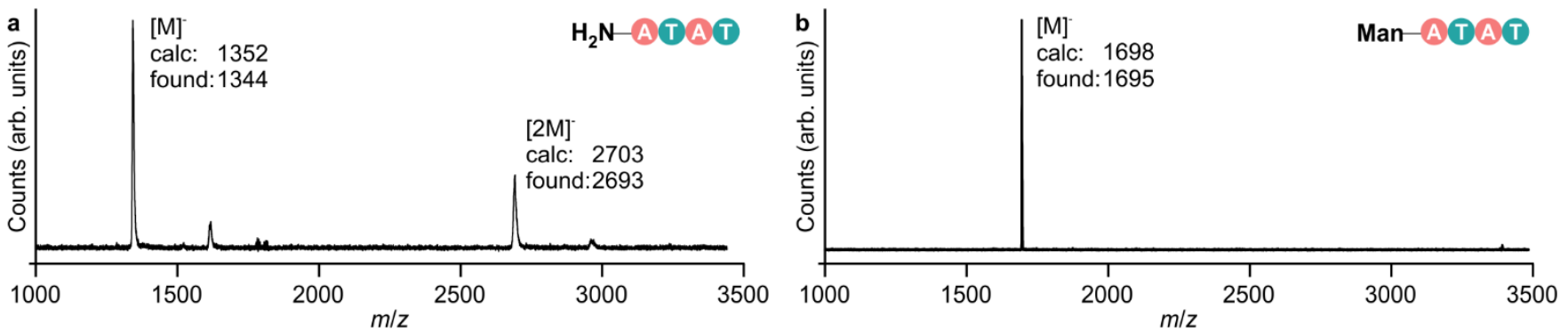

Figure S19. MALDI-TOF MS of a representative DNA glycoconjugation reaction $\left(\mathrm{Man}-8+\mathrm{H}_{2} \mathrm{~N}-\mathrm{ATAT}\right)$. (a) Purified oligonucleotide $\mathrm{H}_{2} \mathrm{~N}-\mathrm{ATAT}$ (9). (b) Purified DNA glycoconjugate Man-ATAT (10). 


\subsection{Determination of Extinction Coefficient for Squaramide Linker}

The squaramide moiety in the DNA glycoconjugates (10) absorbs significantly at $260 \mathrm{~nm}$. To permit accurate quantification of the glycoconjugation by UV absorbance, the extinction coefficient of the squaramide group at $260 \mathrm{~nm}\left(\varepsilon_{260}\right)$ was determined. A known mass (1.12 g) of a model squaramide (Man-11) was dissolved in a known quantity of water $(9.4 \mathrm{~mL})$. Parallel dilutions of this stock solution were prepared and their absorbance at $260 \mathrm{~nm}$ $\left(\mathrm{A}_{260}\right)$ was measured on a Cary $5000 \mathrm{UV}$-vis spectrophotometer with a path length, $l$, of $1 \mathrm{~cm}$. A Beer's law plot of $\mathrm{A}_{260}$ against $c$ yielded a linear plot with gradient $m=\varepsilon_{260}=10800 \mathrm{M}^{-1} \mathrm{~cm}^{-1}$ (Figure S20).
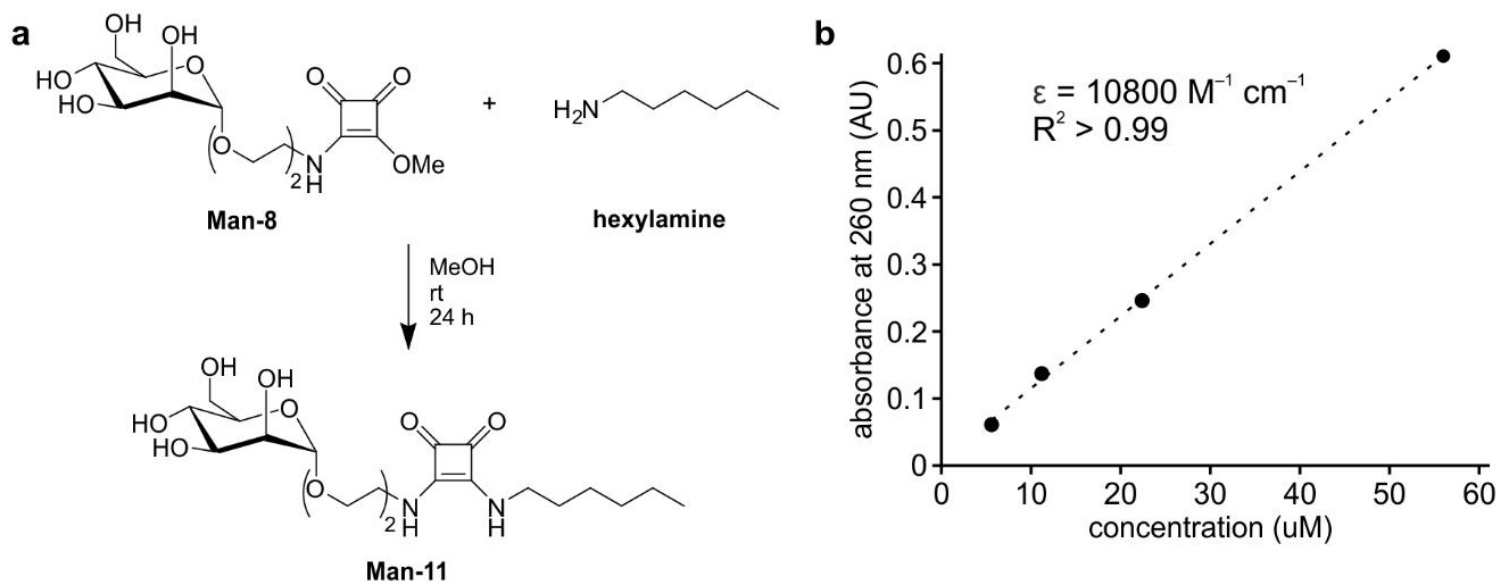

Figure S20. Determination of the extinction coefficient of the squaramide linker. (a) Synthesis of model mannose-squaramide, Man-11. (b) Beer's law plot of aqueous solutions of Man-11.

Synthesis of 1-O-(2-(Hexylamido-2-squaramidoethoxy)ethyl)-D-mannopyranose (Man-11). To a solution of Man-8 (54 mg, $0.14 \mathrm{mmol})$ in $\mathrm{MeOH}(10 \mathrm{~mL})$ was added hexylamine (189 $\mu \mathrm{L}, 1.4 \mathrm{mmol}, 10$ equiv). The solution was stirred at $\mathrm{rt}$ for $24 \mathrm{~h}$. The reaction mixture was purified directly by flash column chromatography on silica gel (eluent: $0-100 \% \mathrm{MeOH}$ in $\mathrm{CH}_{2} \mathrm{Cl}_{2}$ ) to give Man-8 as a colorless oil (22 mg, 34\% yield).

${ }^{1} \mathrm{H}$ NMR (CD $\mathrm{CD}_{3} \mathrm{OD}, 400 \mathrm{MHz}$ ): $\delta 4.78$ (d, $J=1.7 \mathrm{~Hz}, 1 \mathrm{H}$ ), 3.93-3.74 (overlapping $\mathrm{m}, 5 \mathrm{H}$ ), 3.65 (overlapping m, $11 \mathrm{H}), 3.34(\mathrm{~s}, 1 \mathrm{H}), 1.68-1.52(\mathrm{~m}, 2 \mathrm{H}), 1.45-1.22(\mathrm{~m}, 6 \mathrm{H}), 0.99-0.81(\mathrm{~m}, 3 \mathrm{H})$. ESI/MS m/z: $[\mathrm{M}+\mathrm{Na}]^{+}$calcd for $\mathrm{C}_{20} \mathrm{H}_{34} \mathrm{~N}_{2} \mathrm{O}_{9} \mathrm{Na} 469.22$; found 469.24 


\section{ConA-DNA Glycoconjugate Binding Experiment}

To confirm that ConA is able to bind mannose-DNA conjugates, a fluorescence competition binding assay was conducted with 4-methylumbelliferyl $\alpha$-D-mannopyranoside (Aldrich; MUM, Figure S21). ${ }^{8}$ Upon excitation at $325 \mathrm{~nm}$, free MUM in solution fluoresces at $382 \mathrm{~nm}$ but this fluorescence is quenched upon binding by ConA (Figure S21a). In the competition binding assay, ConA $(60 \mu \mathrm{M})$ was first mixed with MUM $(20 \mu \mathrm{M})$. Man-DNA was subsequently added at different concentrations, leading to a fluorescence turn-on (Figure S21b, c, black), suggesting that the presence of Man-DNA in solution recovers the fluorescence of MUM. To confirm that this turnon was mediated by a specific interaction between ConA and the mannose-containing conjugate, the assay was repeated with Gal-DNA and an oligonucleotide not containing sugar, $\mathrm{NH}_{2}$-DNA (Figure $\mathrm{S} 21 \mathrm{c}$, red and blue, respectively). The specificity of the interaction between Man-DNA and ConA is supported by the lack of a fluorescence turn-on with Gal-DNA and $\mathrm{NH}_{2}$-DNA. All samples were measured at $25{ }^{\circ} \mathrm{C}$, in triplicate, with a reaction volume of $100 \mu \mathrm{L}$, using a BioTek Cytation 5 multi-mode imaging system.

(a)
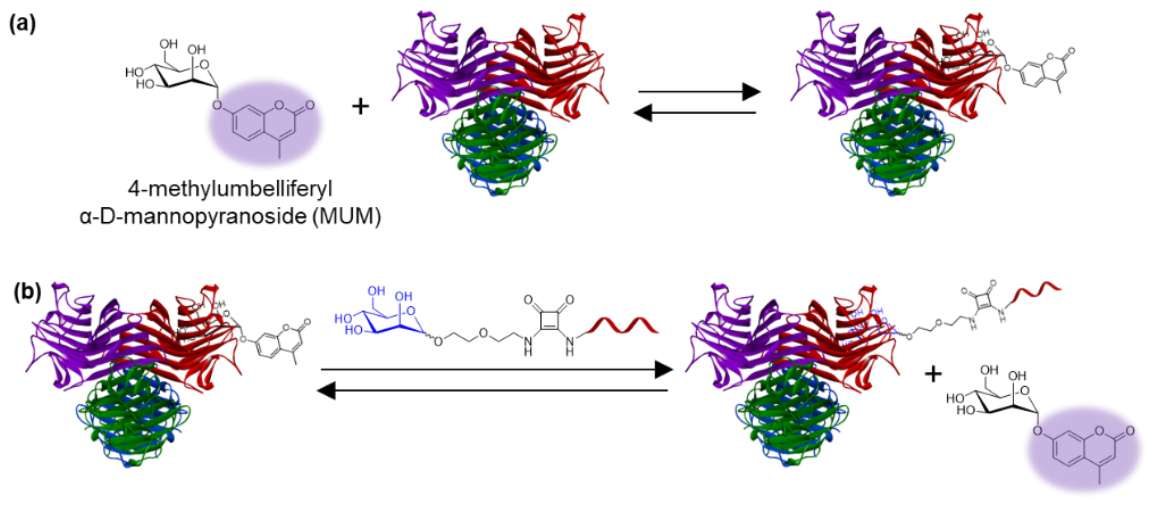

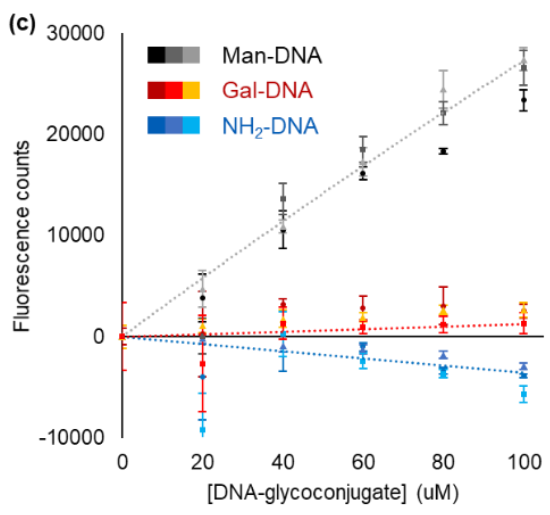

Figure S21. Fluorescence competition binding assay. (a) Unbound MUM is fluorescent (indicated by purple ellipse). Binding of MUM by ConA turns off MUM fluorescence. (b) Binding of a DNA glycoconjugate by ConA displaces MUM, resulting in fluorescence turn-on. (c) Plot of fluorescence intensity against concentration of DNA glycoconjugate. Man- and Gal-DNA are DNA glycoconjugates with mannose and galactose, respectively, while $\mathrm{NH}_{2}$-DNA denotes an amine-terminated DNA strand not conjugated to a sugar. Initial concentrations: [ConA] = $60 \mu \mathrm{M},[\mathrm{MUM}]=20 \mu \mathrm{M}$. 


\section{Structural Analysis of Single Crystals of ConA and DNA Glycoconjugates}

\subsection{Crystallization of ConA with DNA Glycoconjugates}

Mixtures of ConA (Aldrich, Type VI, cat. no. L7647, used as received) and DNA glycoconjugates were screened for crystallization using the sitting-drop vapor-diffusion technique. ${ }^{9}$ In a typical experiment, a solution containing ConA (32 or $40 \mu \mathrm{M}$ with respect to monomer) and a DNA glycoconjugate ( 2 or 4 equiv with respect to ConA) was prepared in a buffer containing Tris $(20 \mathrm{mM}, \mathrm{pH}), \mathrm{NaCl}(100 \mathrm{mM}), \mathrm{MnCl}_{2}(1 \mathrm{mM})$, and $\mathrm{CaCl}_{2}(1 \mathrm{mM})$. Crystallization screening experiments were set up in a 96-well plate (Intelli-Plate 96-3 well, Art Robbins Instruments) using a Crystal Gryphon liquid-handling robot (Art Robbins Instruments) and the Helix screen of crystallization conditions (Molecular Dimensions). In the 96-well plate, each reservoir was charged with $70 \mu \mathrm{L}$ of the crystallization condition, and each sitting drop comprised $1 \mu \mathrm{L}$ of the crystallization condition and $1 \mu \mathrm{L}$ of the ConA-DNA solution. Plates were incubated at $22{ }^{\circ} \mathrm{C}$ undisturbed for 2 to 3 weeks and then manually surveyed under a light microscope. Crystals were transferred to nylon loops and frozen immediately in liquid nitrogen. Diffraction data were collected at the Life Sciences Collaborative Access Team (LS-CAT) beamlines 21-ID-D, -F, and $-\mathrm{G}$ at the Advanced Photon Source, Argonne National Laboratory.

Crystals were obtained under multiple conditions for most of the DNA conjugates investigated. In all cases, all crystals obtained for a given DNA design were solved in the same space group with near-identical unit cell parameters (Table S2). Models were built and refined for the highest-resolution diffraction data for each structure (Table 1, grey-filled entries in Table S2, and Tables S3-S5). 
Table S2. Crystallization Conditions and Crystal Structure Parameters for Crystals Obtained from Mixtures of ConA and DNA, Sorted by Structure and Grouped by DNA Glycoconjugate ${ }^{\text {a }}$

\begin{tabular}{|c|c|c|c|c|c|c|c|}
\hline Structure & DNA & $\begin{array}{c}{[\mathrm{Con} A]} \\
(\mathbf{u M})^{\mathbf{b}}\end{array}$ & $\begin{array}{c}\text { [DNA] } \\
(\mathbf{u M})\end{array}$ & $\begin{array}{l}\text { Helix } \\
\text { condition }\end{array}$ & Components $^{\mathrm{c}}$ & $\begin{array}{l}\text { Space } \\
\text { group }\end{array}$ & $\begin{array}{c}\text { Unit cell } \\
a, b, c(\AA) ; \\
\alpha, \beta, \gamma\left({ }^{\circ}\right)\end{array}$ \\
\hline I & - & 32 & - & H3 & $\begin{array}{c}0.1 \mathrm{M} \text { potassium chloride, } 0.005 \mathrm{M} \text { barium chloride dihydrate, } \\
0.05 \mathrm{M} \text { bis-Tris }(\mathrm{pH} 7), 12 \% \text { w/v PEG } 8000\end{array}$ & $I 222$ & $\begin{array}{l}61,85,89 \\
90,90,90\end{array}$ \\
\hline I & Man-8 & 32 & 128 & B6 & $\begin{array}{l}0.1 \mathrm{M} \text { sodium chloride, } 0.005 \mathrm{M} \text { strontium chloride } \\
\text { hexahydrate, } 0.05 \mathrm{M} \text { MES (pH 6.5), } 17 \% \text { w/v PEG } 4000\end{array}$ & $I 222$ & $\begin{array}{l}61,86,90 \\
90,90,90\end{array}$ \\
\hline I & ATAT & 32 & 128 & D11 & $\begin{array}{l}0.2 \mathrm{M} \text { lithium chloride, } 0.05 \mathrm{M} \text { bis-Tris ( } \mathrm{pH} 7 \text { ), } 22 \% \mathrm{w} / \mathrm{v} \\
\text { PEG } 2000 \mathrm{MME}\end{array}$ & $I 222$ & $\begin{array}{l}62,86,89 \\
90,90,90\end{array}$ \\
\hline I & AGCT & 32 & 128 & B5 & $\begin{array}{l}0.1 \mathrm{M} \text { lithium chloride, } 0.01 \mathrm{M} \text { manganese(II) chloride } \\
\text { tetrahydrate, } 0.05 \mathrm{M} \text { MES (pH 6.5), } 17 \% \text { w/v PEG } 4000\end{array}$ & $I 222$ & $\begin{array}{l}61,86,90 \\
90,90,90\end{array}$ \\
\hline I & AGCT & 32 & 128 & H10 & $\begin{array}{l}0.05 \mathrm{M} \text { lithium sulfate, } 0.03 \mathrm{M} \text { magnesium sulfate heptahydrate, } \\
0.05 \mathrm{M} \text { bis-Tris ( } \mathrm{pH} 8), 15 \% \mathrm{w} / \mathrm{v} \text { PEG } 3350\end{array}$ & $I 222$ & $\begin{array}{l}61,86,89 \\
90,90,90\end{array}$ \\
\hline I & Gal-ATAT & 32 & 128 & H9 & $\begin{array}{l}0.1 \mathrm{M} \text { potassium chloride, } 0.002 \mathrm{M} \text { spermine tetrahydrochloride, } \\
0.05 \mathrm{M} \text { bis-Tris ( } \mathrm{pH} 7.5), 7 \% \mathrm{w} / \mathrm{v} \text { PEG } 8000\end{array}$ & $I 222$ & $\begin{array}{l}62,86,89 \\
90,90,90\end{array}$ \\
\hline I & Gal-AGCT & 32 & 128 & H10 & $\begin{array}{l}0.05 \mathrm{M} \text { lithium sulfate, } 0.03 \mathrm{M} \text { magnesium sulfate heptahydrate, } \\
0.05 \mathrm{M} \text { bis-Tris }(\mathrm{pH} 8), 15 \% \mathrm{w} / \mathrm{v} \text { PEG } 3350\end{array}$ & $I 222$ & $\begin{array}{l}62,86,90 \\
90,90,90\end{array}$ \\
\hline II & Man-AGCT & 40 & 160 & D3 & $0.2 \mathrm{M}$ lithium sulfate, $0.05 \mathrm{M}$ bis-Tris ( $\mathrm{pH} 7), 20 \% \mathrm{v} / \mathrm{v}$ MPD & $P 2{ }_{1} 22_{1}$ & $\begin{array}{l}66,71,126 \\
90,90,90\end{array}$ \\
\hline II & Man-AGCT & 32 & 128 & E5 & $0.05 \mathrm{M}$ lithium sulfate, $0.05 \mathrm{M}$ HEPES (pH 6.5), $15 \%$ v/v MPD & $P 2_{1} 22_{1}$ & $\begin{array}{l}66,71,126 \\
90,90,90\end{array}$ \\
\hline II & Man-AGCT & 32 & 128 & A4 & $\begin{array}{l}0.2 \mathrm{M} \text { potassium chloride, } 0.005 \mathrm{M} \text { hexammine cobalt(III) } \\
\text { chloride, } 0.05 \mathrm{M} \text { MES ( } \mathrm{pH} 6.5), 25 \% \mathrm{v} / \mathrm{v} \text { PEG } 400\end{array}$ & $P 2{ }_{1} 22_{1}$ & $\begin{array}{l}66,70,125 \\
90,90,90\end{array}$ \\
\hline II & Man-ATAT & 40 & 160 & D9 & $\begin{array}{c}0.05 \mathrm{M} \text { bis-Tris ( } \mathrm{pH} 7), 2 \mathrm{M} \text { ammonium sulfate, } 5 \% \mathrm{v} / \mathrm{v} \\
\text { PEG } 400\end{array}$ & $P 2{ }_{1} 22_{1}$ & $\begin{array}{l}66,71,126 \\
90,90,90\end{array}$ \\
\hline II & Man-ATAT & 40 & 160 & D9 & $\begin{array}{c}0.05 \mathrm{M} \text { bis-Tris ( } \mathrm{pH} 7 \text { ), } 2 \mathrm{M} \text { ammonium sulfate, } 5 \% \mathrm{v} / \mathrm{v} \\
\text { PEG } 400\end{array}$ & $P 2{ }_{1} 22_{1}$ & $\begin{array}{l}66,71,126 \\
90,90,90\end{array}$ \\
\hline II & Man-ATAT & 40 & 160 & F7 & $\begin{array}{l}0.3 \mathrm{M} \text { lithium sulfate, } 0.05 \mathrm{M} \text { bis-Tris }(\mathrm{pH} 7), 18 \% \mathrm{w} / \mathrm{v} \\
\text { PEG } 1000\end{array}$ & $P 2{ }_{1} 22_{1}$ & $\begin{array}{l}66,71,125 \\
90,90,90\end{array}$ \\
\hline II & Man-ATAT & 32 & 128 & $\mathrm{~B} 8$ & $\begin{array}{c}\text { 2.6 M sodium malonate dibasic monohydrate, } 0.001 \mathrm{M} \text { spermine } \\
\text { tetrahydrochloride, } 0.05 \mathrm{M} \text { MES }(\mathrm{pH} 6.5)\end{array}$ & $P 2{ }_{1} 22_{1}$ & $\begin{array}{l}65,71,126 \\
90,90,90\end{array}$ \\
\hline
\end{tabular}




\begin{tabular}{|c|c|c|c|c|c|c|c|}
\hline Structure & DNA & $\begin{array}{c}{[\operatorname{Con} A]} \\
(\mathbf{u M})^{b}\end{array}$ & $\begin{array}{l}\text { [DNA] } \\
(\mathbf{u M})\end{array}$ & $\begin{array}{l}\text { Helix } \\
\text { condition }\end{array}$ & Components $^{c}$ & $\begin{array}{l}\text { Space } \\
\text { group }\end{array}$ & $\begin{array}{l}\text { Unit cell } \\
a, b, c(\AA) \\
\alpha, \beta, \gamma\left({ }^{\circ}\right)\end{array}$ \\
\hline II & Man-CGCG & 80 & 160 & D9 & $\begin{array}{c}0.05 \mathrm{M} \text { bis-Tris (pH 7), } 2 \mathrm{M} \text { ammonium sulfate, } 5 \% \mathrm{v} / \mathrm{v} \\
\text { PEG } 400\end{array}$ & $P 2{ }_{1} 22_{1}$ & $\begin{array}{l}66,70,126 \\
90,90,90\end{array}$ \\
\hline II & Man-GTAC & 32 & 128 & A4 & $\begin{array}{l}0.2 \mathrm{M} \text { potassium chloride, } 0.005 \mathrm{M} \text { hexammine cobalt(III) } \\
\text { chloride, } 0.05 \mathrm{M} \text { MES (pH 6.5), 25\% v/v PEG } 400\end{array}$ & $P 2{ }_{1} 22_{1}$ & $\begin{array}{l}66,70,125 \\
90,90,90\end{array}$ \\
\hline II & $\begin{array}{l}\text { Man-TTTT + } \\
\text { Man-AAAA }\end{array}$ & 32 & $128^{d}$ & B5 & $\begin{array}{l}0.1 \mathrm{M} \text { lithium chloride, } 0.01 \mathrm{M} \text { manganese(II) chloride } \\
\text { tetrahydrate, } 0.05 \mathrm{M} \text { MES (pH 6.5), } 17 \% \text { w/v PEG } 4000\end{array}$ & $P 2{ }_{1} 22_{1}$ & $\begin{array}{l}66,70,125 \\
90,90,90\end{array}$ \\
\hline II & $\begin{array}{l}\text { Man-TTTT + } \\
\text { Man-AAAA }\end{array}$ & 32 & $64^{d}$ & $\mathrm{H} 12$ & $\begin{array}{l}0.052 \mathrm{M} \text { magnesium chloride hexahydrate, } 0.05 \mathrm{M} \text { bis-Tris } \\
\qquad(\mathrm{pH} 8.5), 18 \% \mathrm{w} / \mathrm{v} \text { PEG } 3350\end{array}$ & $P 2{ }_{1} 22_{1}$ & $\begin{array}{l}65,72,125 \\
90,90,90\end{array}$ \\
\hline II & $\begin{array}{l}\text { Man-TTTT + } \\
\text { Man-AAAA }\end{array}$ & 32 & $64^{\mathrm{d}}$ & B6 & $\begin{array}{c}0.1 \mathrm{M} \text { sodium chloride, } 0.005 \mathrm{M} \text { strontium chloride } \\
\text { hexahydrate, } 0.05 \mathrm{M} \text { MES (pH 6.5), 17\% w/v PEG } 4000\end{array}$ & $P 2{ }_{1} 22_{1}$ & $\begin{array}{l}65,70,126 \\
90,90,90\end{array}$ \\
\hline II & $\begin{array}{l}\text { Man-TTTT + } \\
\text { Man-AAAA }\end{array}$ & 32 & $128^{\mathrm{d}}$ & $\mathrm{H} 5$ & $\begin{array}{c}0.05 \mathrm{M} \text { sodium chloride, } 0.2 \mathrm{M} \text { lithium chloride, } 0.01 \mathrm{M} \\
\text { calcium chloride dihydrate, } 0.05 \mathrm{M} \text { bis-Tris }(\mathrm{pH} 7), 20 \% \mathrm{w} / \mathrm{v} \\
\text { PEG } 2000\end{array}$ & $P 2{ }_{1} 22_{1}$ & $\begin{array}{l}66,71,125 \\
90,90,90\end{array}$ \\
\hline II & $\begin{array}{l}\text { Man-TTTT + } \\
\text { Man-AAAA }\end{array}$ & 32 & $128^{\mathrm{d}}$ & B3 & $\begin{array}{c}0.1 \mathrm{M} \text { sodium chloride, } 0.05 \mathrm{M} \text { lithium chloride, } 0.01 \mathrm{M} \\
\text { magnesium chloride hexahydrate, } 0.05 \mathrm{M} \text { MES (pH 6.5), } \\
17 \% \text { w/v PEG } 4000\end{array}$ & $P 2{ }_{1} 22_{1}$ & $\begin{array}{l}66,70,125 \\
90,90,90\end{array}$ \\
\hline III & Man-AAATTT & 32 & 64 & A3 & $\begin{array}{c}0.1 \mathrm{M} \text { sodium chloride, } 0.05 \mathrm{M} \text { lithium chloride, } 0.01 \mathrm{M} \\
\text { magnesium chloride hexahydrate, } 0.05 \mathrm{M} \text { MES (pH 6.5), } \\
25 \% \mathrm{v} / \mathrm{v} \text { PEG } 400\end{array}$ & $P 2{ }_{1} 22_{1}$ & $\begin{array}{l}65,78,126 \\
90,90,90\end{array}$ \\
\hline III & Man-AAATTT & 32 & 128 & A1 & $\begin{array}{c}0.05 \mathrm{M} \text { potassium chloride, } 0.1 \mathrm{M} \text { lithium chloride, } 0.012 \mathrm{M} \\
\text { spermine tetrahydrochloride, } 0.05 \mathrm{M} \text { MES (pH 6.5), } 25 \% \mathrm{v} / \mathrm{v} \\
\text { PEG } 400\end{array}$ & $P 2{ }_{1} 22_{1}$ & $\begin{array}{l}66,82,126 \\
90,90,90\end{array}$ \\
\hline III & Man-AAATTT & 32 & 64 & D4 & $\begin{array}{c}1 \mathrm{M} \text { ammonium sulfate, } 0.05 \mathrm{M} \text { bis-Tris ( } \mathrm{pH} 7), 20 \% \mathrm{v} / \mathrm{v} \\
\text { glycerol, } 5 \% \mathrm{w} / \mathrm{v} \text { PEG } 3350\end{array}$ & $P 2{ }_{1} 22_{1}$ & $\begin{array}{l}67,77,126 \\
90,90,90\end{array}$ \\
\hline III & Man-AAATTT & 32 & 128 & A6 & $\begin{array}{l}0.1 \mathrm{M} \text { sodium chloride, } 0.005 \mathrm{M} \text { strontium chloride } \\
\text { hexahydrate, } 0.05 \mathrm{M} \text { MES (pH 6.5), 25\% v/v PEG } 400\end{array}$ & $P 2{ }_{1} 22_{1}$ & $\begin{array}{l}65,77,126 \\
90,90,90\end{array}$ \\
\hline III & Man-AAATTT & 32 & 64 & D4 & $\begin{array}{c}1 \mathrm{M} \text { ammonium sulfate, } 0.05 \mathrm{M} \text { bis-Tris ( } \mathrm{pH} 7), 20 \% \mathrm{v} / \mathrm{v} \\
\text { glycerol, } 5 \% \mathrm{w} / \mathrm{v} \text { PEG } 3350\end{array}$ & $P 2{ }_{1} 22_{1}$ & $\begin{array}{l}66,77,125 \\
90,90,90\end{array}$ \\
\hline IV & G(Man-T)AC & 40 & 160 & H6 & $\begin{array}{l}0.1 \mathrm{M} \text { potassium chloride, } 0.002 \mathrm{M} \text { spermine tetrahydrochloride, } \\
0.05 \mathrm{M} \text { bis-Tris (pH 7), } 15 \% \text { w/v PEG } 2000 \mathrm{MME}\end{array}$ & $P 22_{1} 2_{1}$ & $\begin{array}{l}70,117,123 \\
90,90,90\end{array}$ \\
\hline
\end{tabular}




\begin{tabular}{|c|c|c|c|c|c|c|c|}
\hline Structure & DNA & $\begin{array}{c}{[\text { ConA] }} \\
(\mathrm{uM})^{\mathrm{b}}\end{array}$ & $\begin{array}{c}\text { [DNA] } \\
(\mathbf{u M})\end{array}$ & $\begin{array}{c}\text { Helix } \\
\text { condition }\end{array}$ & Components ${ }^{c}$ & $\begin{array}{l}\text { Space } \\
\text { group }\end{array}$ & $\begin{array}{c}\text { Unit cell } \\
a, b, c(\AA) ; \\
\alpha, \beta, \gamma\left({ }^{\circ}\right)\end{array}$ \\
\hline IV & $\mathrm{A}(\mathrm{Man}-\mathrm{T}) \mathrm{AT}$ & 40 & 160 & $\mathrm{H} 10$ & $\begin{array}{c}0.05 \mathrm{M} \text { lithium sulfate, } 0.03 \mathrm{M} \text { magnesium sulfate heptahydrate, } \\
0.05 \mathrm{M} \text { bis-Tris ( } \mathrm{pH} \text { 8), } 15 \% \text { w/v PEG } 3350\end{array}$ & $P 22_{1} 2_{1}$ & $\begin{array}{l}68,118,123 \\
90,90,90\end{array}$ \\
\hline IV & $\mathrm{A}(\mathrm{Man}-\mathrm{T}) \mathrm{AT}$ & 40 & 160 & $\mathrm{H} 10$ & $\begin{array}{c}0.05 \mathrm{M} \text { lithium sulfate, } 0.03 \mathrm{M} \text { magnesium sulfate heptahydrate, } \\
0.05 \mathrm{M} \text { bis-Tris ( } \mathrm{pH} \text { 8), } 15 \% \text { w/v PEG } 3350\end{array}$ & $P 22_{1} 2_{1}$ & $\begin{array}{l}67,116,121 \\
90,90,90\end{array}$ \\
\hline IV & $\mathrm{A}(\mathrm{Man}-\mathrm{T}) \mathrm{AT}$ & 32 & 128 & H6 & $\begin{array}{c}0.1 \mathrm{M} \text { potassium chloride, } 0.002 \mathrm{M} \text { spermine tetrahydrochloride, } \\
0.05 \mathrm{M} \text { bis-Tris }(\mathrm{pH} 7), 15 \% \mathrm{w} / \mathrm{v} \text { PEG } 2000 \mathrm{MME}\end{array}$ & $P 22_{1} 2_{1}$ & $\begin{array}{l}69,117,122 \\
90,90,90\end{array}$ \\
\hline IV & $\mathrm{A}(\mathrm{Man}-\mathrm{T}) \mathrm{AT}$ & 32 & 128 & H6 & $\begin{array}{l}0.1 \mathrm{M} \text { potassium chloride, } 0.002 \mathrm{M} \text { spermine tetrahydrochloride, } \\
0.05 \mathrm{M} \text { bis-Tris ( } \mathrm{pH} 7), 15 \% \mathrm{w} / \mathrm{v} \text { PEG } 2000 \mathrm{MME}\end{array}$ & $P 22_{1} 2_{1}$ & $\begin{array}{l}70,117,124 \\
90,90,90\end{array}$ \\
\hline IV & $\mathrm{A}(\mathrm{Man}-\mathrm{T}) \mathrm{AT}$ & 32 & 128 & $\mathrm{~F} 2$ & 0.05 M bis-Tris (pH 7), 14\% w/v PEG 2000 MME & $P 22_{1} 2_{1}$ & $\begin{array}{l}70,117,124 \\
90,90,90\end{array}$ \\
\hline $\mathrm{V}$ & $\mathrm{T}($ Man-T)TT & 32 & 128 & B6 & $\begin{array}{l}\text { 0.1 M sodium chloride, } 0.005 \mathrm{M} \text { strontium chloride } \\
\text { hexahydrate, } 0.05 \mathrm{M} \text { MES (pH 6.5), 17\% w/v PEG } 4000\end{array}$ & $P 2_{1}$ & $\begin{array}{c}61,64,127 \\
90,93,90\end{array}$ \\
\hline $\mathrm{V}$ & $\mathrm{T}($ Man-T)TT & 32 & 128 & D11 & $\begin{array}{l}0.2 \mathrm{M} \text { lithium chloride, } 0.05 \mathrm{M} \text { bis-Tris ( } \mathrm{pH} 7 \text { ), } 22 \% \mathrm{w} / \mathrm{v} \text { PEG } \\
2000 \mathrm{MME}\end{array}$ & $P 2_{1}$ & $\begin{array}{l}60,64,126 \\
90,93,90\end{array}$ \\
\hline
\end{tabular}

${ }^{a}$ Grey-filled entries denote crystals with the highest-resolution data for each combination of ConA and DNA glycoconjugate, for which models were built and data have been deposited into the Protein Data Bank. ${ }^{\mathrm{b}}[\mathrm{ConA}]$ is calculated with respect to protein monomer. ${ }^{\mathrm{c}}$ Abbreviations: HEPES 4-(2-hydroxyethyl)-1-piperazineethanesulfonic acid; MES - 2-(N-morpholino)ethanesulfonic acid; MME - monomethyl ether; MPD - 2-methyl2,4-pentanediol; PEG - polyethylene glycol. ${ }^{\mathrm{d}}$ [DNA] denotes total DNA concentration; the glycoconjugates Man-TTTT and Man-AAAA were mixed in a 1:1 molar ratio. 


\subsection{Structure Solution and Model Refinement}

Data processing, structure solution, and model refinement were conducted using the CCP4 suite of programs. ${ }^{10}$ Diffraction data were indexed and integrated with iMosflm. ${ }^{11}$ The space group and unit cell parameters were confirmed with Pointless. ${ }^{12}$ Data were scaled and merged using Scala using a resolution cut-off criterion, mean $I /(\sigma(I)) \approx 2.5$, for the highest-resolution bin. ${ }^{12}$ Structures were determined by molecular replacement with PhaserMR, using a single monomer of ConA (PDB: $1 \mathrm{JBC}^{13}$ or $5 \mathrm{CNA}^{14}$ ) as an initial model. The number of copies sought during molecular replacement was determined using the Matthews module of CCP4. ${ }^{15,16}$ The initial molecular replacement solution was refined with Refmac ${ }^{17,18}$ using 100 cycles of jelly-body refinement and automatically-generated local NCS restraints. The model of the protein chain was improved via successive rounds of manual model building in $\operatorname{Coot}^{19}$ and subsequent refinement in Refmac using rigid-body refinement, until values of $R_{\text {work }} / R_{\text {free }}$ were unchanged. In most structures, there are amino acid residues in loop regions that are unmodelled due to poor electron density, particularly residues 116-122. For residues where the conformation of the side chain could not be unambiguously determined due to disorder, the side chains were trimmed so that the model only includes atoms that can be resolved from electron density.

For structures where electron density was observed only for the mannose-squaramide linker, an atomic model for the linker was constructed in acedrg ${ }^{20,21}$ and its coordinates were imported into Coot with the refined protein model. One instance of the linker was manually placed in the electron density within the mannose-binding pocket, and then subjected to free-body refinement within Coot and one round of refinement in Refmac. The linker was subsequently copied to all other monomers in the protein structure using Coot's 'Find NCS Ligands' function. The model was refined through successive rounds of manual model building in Coot and refinement in Refmac until values of $R_{\text {work }} / R_{\text {free }}$ were unchanged.

For structures where at least partial electron density was observed also for the oligonucleotide, an atomic model for a single-stranded oligonucleotide was constructed using Coot's in-built nucleic acid builder and its coordinates imported into Coot with the refined protein model and the coordinates for a single mannose-squaramide linker. The nucleic acid was manually placed in the electron density within Coot, and the bond between the nucleic acid and the mannose-squaramide linker was defined in the PDB file using the LNK remark. The linked mannoseDNA glycoconjugate was then copied to all other sites in the protein model using Coot's 'Find NCS Ligands' function. The full model was refined in Refmac, using $\operatorname{libg}^{22}$ to generate external restraints for the DNA double helix according to user-input chain definitions. An all-atom model for the oligonucleotide (excluding hydrogens) was included during refinement and in the final deposited model, even where the position of backbone atoms could not be unambiguously determined due to disorder. The occupancies for all atoms were set to 1.00 and associated temperature factors $(B)$ were unconstrained during refinement. The model was refined through successive rounds of manual model building in Coot and refinement in Refmac until values of $R_{\text {work }} / R_{\text {free }}$ were unchanged. 
For all structures, water molecules were added in Coot and refined in Refmac until values of $R_{\text {work }} / R_{\text {free }}$ were unchanged and steric clashes identified by the wwPDB validation server were minimized. A final round of refinement in Refmac was conducted to finalize the model. Parameters pertaining to the structure elucidation and model refinement for crystals are summarized for structure I in Table S3, for structure II in Table S4, and for structures II, IV, and V in Table S5.

A Note on Non-Crystallographic Symmetry. The intrinsic $D_{2}$ symmetry of ConA and the presence of multiple copies of the protein within the unit cell results in translational non-crystallographic symmetry (tNCS $)^{23}$ in structure IV (PDB: 7MGB and 7MGC). The presence of tNCS complicated determination of the exact space group for this structure. Consequently, diffraction data were indexed, integrated, and scaled as described above for all space groups within the point group $P 222$. Molecular replacement was performed for each of these structures individually, and the initial model solutions were refined with Refmac. At this point, the $R_{\text {work }} / R_{\text {free }}$ values for these structures represented a bimodal distribution with either $R_{\mathrm{work}} / R_{\text {free }}>45 \%$ or $R_{\mathrm{work}} / R_{\text {free }}<35 \%$; the former group were discarded as inviable solutions at this point. The space groups of the remaining viable solutions were analyzed with Zanuda ${ }^{24}$ and $P 22_{1} 2_{1}$ was selected as the most probable space group. The molecular replacement solution for $P 22_{1} 2_{1}$ was processed and refined as described above. 
Table S3. Summary of Crystallization Data and Structural and Model Refinement Parameters of Crystals with Structure I

\begin{tabular}{|c|c|c|c|c|}
\hline & $\begin{array}{c}\text { ConA } \\
\text { (protein only) }\end{array}$ & $\begin{array}{c}\text { ConA + Man-8 } \\
\text { (sugar squaramide, no DNA) }\end{array}$ & $\begin{array}{c}\text { ConA + ATAT } \\
(\mathrm{DNA}, \text { no sugar })\end{array}$ & $\begin{array}{r}\text { ConA + Gal-ATAT } \\
\text { (non-binding sugar) }\end{array}$ \\
\hline Structure & I & I & I & I \\
\hline PDB Code & 7MG1 & $7 \mathrm{MG} 2$ & 7MG3 & 7MG4 \\
\hline Unit cell: $a, b, c(\AA)$ & $61.19,85.18,89.25$ & $61.42,86.13,89.50$ & $62.07,86.39,89.32$ & $61.63,86.03,89.23$ \\
\hline Unit cell: $\alpha, \beta, \gamma\left(^{\circ}\right)$ & $90.00,90.00,90.00$ & $90.00,90.00,90.00$ & $90.00,90.00,90.00$ & $90.00,90.00,90.00$ \\
\hline Space group & $I 222$ & $I 222$ & $I 222$ & $I 222$ \\
\hline Resolution range $(\AA)^{a}$ & $61.62-2.00(2.11-2.00)$ & $62.06-1.80(1.90-1.80)$ & $51.02-1.60(1.69-1.60)$ & $61.93-2.00(2.11-2.00)$ \\
\hline Wavelength $(\AA)$ & 0.979 & 0.979 & 0.979 & 0.979 \\
\hline Observed reflections & 106503 & 204092 & 302412 & 117276 \\
\hline Unique reflections & 14120 & 21234 & 29176 & 14558 \\
\hline Redundancy $^{\mathrm{a}}$ & $7.1(6.3)$ & $9.1(9.0)$ & $9.7(9.9)$ & $7.7(7.1)$ \\
\hline Completeness (\%) ${ }^{\mathrm{a}}$ & $92.2(82.4)$ & $99.8(99.9)$ & $96.1(96.6)$ & $93.4(84.7)$ \\
\hline Mean $(I / \sigma(I))^{\mathrm{a}}$ & $3.2(1.3)$ & $2.6(0.9)$ & $5.6(0.9)$ & $3.1(0.8)$ \\
\hline$R_{\text {meas }}^{\mathrm{a}, \mathrm{b}}$ & $0.121(0.485)$ & $0.157(0.666)$ & $0.111(0.623)$ & $0.123(0.486)$ \\
\hline$R_{\text {work }}$ & 0.203 & 0.183 & 0.181 & 0.179 \\
\hline$R_{\text {free }}$ & 0.262 & 0.230 & 0.213 & 0.237 \\
\hline RMSD bond lengths $(\AA)$ & 0.008 & 0.010 & 0.012 & 0.009 \\
\hline RMSD bond angles $\left({ }^{\circ}\right)$ & 1.516 & 1.560 & 1.699 & 1.566 \\
\hline Avg. B, protein $\left(\AA^{2}\right)$ & 19.8 & 14.8 & 15.6 & 17.6 \\
\hline Avg. B, water $\left(\AA^{2}\right)$ & 36.7 & 41.5 & 38.3 & 43.6 \\
\hline $\begin{array}{l}\text { Favored and allowed } \\
\text { regions }(\%)^{c}\end{array}$ & 100.0 & 100.0 & 100.0 & 100.0 \\
\hline Disallowed regions $(\%)^{\mathrm{c}}$ & 0.0 & 0.0 & 0.0 & 0.0 \\
\hline Solvent content $(\%)^{\mathrm{d}}$ & 46 & 47 & 47 & 47 \\
\hline
\end{tabular}

${ }^{a}$ Values in parentheses refer to the highest-resolution shell. ${ }^{\mathrm{b}} R_{\text {meas }}$ is a multiplicity-independent measure of data quality. ${ }^{25} \mathrm{c}$ Torsional analysis of amino acid backbone by Ramachandran plot. ${ }^{d}$ Solvent content determined using Matthews coefficient calculator. ${ }^{26}$ 
Table S4. Summary of Crystallization Data and Structural and Model Refinement Parameters of Crystals with Structure II

\begin{tabular}{|c|c|c|c|c|c|}
\hline & $\begin{array}{c}\text { ConA + Man-ATAT } \\
\text { (4-bp, terminal, } \\
\text { self-complementary) }\end{array}$ & $\begin{array}{c}\text { ConA + Man-AGCT } \\
\text { (4-bp, terminal, } \\
\text { self-complementary) }\end{array}$ & $\begin{array}{c}\text { ConA + Man-GTAC } \\
\text { (4-bp, terminal, } \\
\text { self-complementary) }\end{array}$ & $\begin{array}{c}\text { ConA + Man-CGCG } \\
\text { (4-bp, terminal, } \\
\text { self-complementary) }\end{array}$ & $\begin{array}{c}\text { ConA + Man-TTTT + } \\
\text { Man-AAAA } \\
\text { (4-bp, terminal, } \\
\text { complementary) }\end{array}$ \\
\hline Structure & II & II & II & II & II \\
\hline PDB Code & 7MG5 & 7MG6 & 7MG7 & 7MG8 & 7MG9 \\
\hline Unit cell: $a, b, c(\AA)$ & $65.69,70.70,125.87$ & $65.73,70.89,125.84$ & $65.87,70.40,125.09$ & $66.42,69.92,125.87$ & $65.98,70.18,124.42$ \\
\hline Unit cell: $\alpha, \beta, \gamma\left({ }^{\circ}\right)$ & $90.00,90.00,90.00$ & $90.00,90.00,90.00$ & $90.00,90.00,90.00$ & $90.00,90.00,90.00$ & $90.00,90.00,90.00$ \\
\hline Space group & $P 2_{1} 22_{1}$ & $P 2{ }_{1} 22_{1}$ & $P 2{ }_{1} 22_{1}$ & $P 2_{1} 22_{1}$ & $P 2{ }_{1} 22_{1}$ \\
\hline Resolution range $(\AA)^{a}$ & $63.01-2.10(2.21-2.10)$ & $70.89-1.70(1.79-1.70)$ & $62.62-1.75(1.84-1.75)$ & $69.92-3.00(3.16-3.00)$ & $70.18-2.55(2.69-2.55)$ \\
\hline Wavelength $(\AA)$ & 1.0782 & 1.0782 & 0.979 & 1.1271 & 0.979 \\
\hline Observed reflections & 253315 & 570683 & 455059 & 114717 & 59147 \\
\hline Unique reflections & 32700 & 61815 & 50644 & 11395 & 17243 \\
\hline Redundancy ${ }^{\text {a }}$ & $7.3(7.7)$ & $8.8(9.0)$ & $8.5(8.3)$ & $9.4(10.1)$ & $3.3(2.9)$ \\
\hline Completeness (\%) ${ }^{\mathrm{a}}$ & $98.3(99.9)$ & $99.6(99.9)$ & $89.8(99.9)$ & $98.2(99.9)$ & $93.1(86.0)$ \\
\hline Mean $(I / \sigma(I))^{\text {a }}$ & $7.1(2.6)$ & $2.7(3.0)$ & $6.5(1.4)$ & $2.5(1.1)$ & $5.9(2.7)$ \\
\hline$R_{\text {meas }}^{\mathrm{a}, \mathrm{b}}$ & $0.074(0.315)$ & $0.104(0.250)$ & $0.073(0.578)$ & $0.209(0.693)$ & $0.223(0.744)$ \\
\hline$R_{\text {work }}$ & 0.201 & 0.177 & 0.186 & 0.233 & 0.250 \\
\hline$R_{\text {free }}$ & 0.245 & 0.207 & 0.215 & 0.284 & 0.314 \\
\hline RMSD bond lengths $(\AA)$ & 0.011 & 0.014 & 0.014 & 0.008 & 0.008 \\
\hline RMSD bond angles $\left({ }^{\circ}\right)$ & 1.540 & 1.689 & 1.634 & 1.593 & 1.503 \\
\hline Avg. B, protein $\left(\AA^{2}\right)$ & 32.0 & 22.6 & 24.4 & 61.7 & 33.1 \\
\hline Avg. B, water $\left(\AA^{2}\right)$ & 47.6 & 40.9 & 40.5 & 56.6 & 29.4 \\
\hline $\begin{array}{l}\text { Favored and allowed } \\
\text { regions }(\%)^{c}\end{array}$ & 100.0 & 100.0 & 100.0 & 100.0 & 100.0 \\
\hline Disallowed regions $(\%)^{\mathrm{c}}$ & 0.0 & 0.0 & 0.0 & 0.0 & 0.0 \\
\hline Solvent content $(\%)^{\mathrm{d}}$ & 54 & 54 & 54 & 54 & 53 \\
\hline
\end{tabular}

${ }^{\mathrm{a}}$ Values in parentheses refer to the highest-resolution shell. ${ }^{\mathrm{b}} R_{\text {meas }}$ is a multiplicity-independent measure of data quality. ${ }^{25} \mathrm{c}$ Torsional analysis of amino acid backbone by Ramachandran plot. ${ }^{\mathrm{d}}$ Solvent content determined using Matthews coefficient calculator. ${ }^{26}$ 
Table S5. Summary of Crystallization Data and Structural and Model Refinement Parameters of Crystals with Structures III, IV, and V

\begin{tabular}{|c|c|c|c|c|}
\hline & $\begin{array}{c}\text { ConA + Man-AAATTT } \\
\text { (6-bp, terminal, } \\
\text { self-complementary) }\end{array}$ & $\begin{array}{c}\text { ConA + A(Man-T)AT } \\
\text { (4-bp, internal, } \\
\text { self-complementary })\end{array}$ & $\begin{array}{c}\text { ConA + G(Man-T)AC } \\
\quad(4-b p, \text { internal, } \\
\text { self-complementary) }\end{array}$ & $\begin{array}{c}\text { ConA + T(Man-T)TT } \\
\text { (4-bp, internal, } \\
\text { non-complementary) }\end{array}$ \\
\hline Structure & III & IV & IV & $\mathrm{V}$ \\
\hline PDB Code & $7 \mathrm{MGA}$ & $7 \mathrm{MGB}$ & $7 \mathrm{MGC}$ & $7 \mathrm{MGD}$ \\
\hline Unit cell: $a, b, c(\AA)$ & $65.09,77.78,126.06$ & $68.01,117.48,122.49$ & $69.33,117.34,122.40$ & $60.56,63.97,126.45$ \\
\hline Unit cell: $\alpha, \beta, \gamma\left(^{\circ}\right)$ & $90.00,90.00,90.00$ & $90.00,90.00,90.00$ & $90.00,90.00,90.00$ & $90.00,93.30,90.00$ \\
\hline Space group & $P 2{ }_{1} 22_{1}$ & $P 22_{1} 2_{1}$ & $P 22_{1} 2_{1}$ & $P 12_{1} 1$ \\
\hline Resolution range $(\AA)^{\text {a }}$ & $57.90-2.00(2.11-2.00)$ & $84.79-2.45(2.58-2.45)$ & $84.70-2.92(3.08-2.92)$ & $60.53-2.05(2.16-2.05)$ \\
\hline Wavelength $(\AA)$ & 1.1271 & 1.0782 & 1.0782 & 0.979 \\
\hline Observed reflections & 125356 & 260367 & 153972 & 138751 \\
\hline Unique reflections & 37677 & 33189 & 19900 & 52751 \\
\hline Redundancy $^{\mathrm{a}}$ & $3.2(3.2)$ & $7.4(7.5)$ & $7.4(8.0)$ & $2.5(2.5)$ \\
\hline Completeness $(\%)^{\mathrm{a}}$ & $90.1(83.4)$ & $94.9(99.9)$ & $84.7(99.8)$ & $91.5(83.4)$ \\
\hline Mean $(I / \sigma(I))^{\mathrm{a}}$ & $4.6(0.8)$ & $4.0(0.9)$ & $4.1(1.4)$ & $3.3(2.4)$ \\
\hline$R_{\text {meas }}{ }^{\mathrm{a}, \mathrm{b}}$ & $0.129(0.844)$ & $0.158(0.888)$ & $0.160(0.599)$ & $0.075(0.414)$ \\
\hline$R_{\text {work }}$ & 0.196 & 0.213 & 0.229 & 0.210 \\
\hline$R_{\text {free }}$ & 0.229 & 0.262 & 0.277 & 0.255 \\
\hline RMSD bond lengths $(\AA)$ & 0.012 & 0.009 & 0.007 & 0.007 \\
\hline RMSD bond angles $\left({ }^{\circ}\right)$ & 1.623 & 1.637 & 1.539 & 1.464 \\
\hline Avg. B, protein $\left(\AA^{2}\right)$ & 24.8 & 37.4 & 53.0 & 29.8 \\
\hline Avg. B, water $\left(\AA^{2}\right)$ & 43.0 & 38.0 & 50.2 & 44.2 \\
\hline $\begin{array}{l}\text { Favored and allowed } \\
\text { regions }(\%)^{\mathrm{c}}\end{array}$ & 100.0 & 99.9 & 99.9 & 100.0 \\
\hline Disallowed regions $(\%)^{\mathrm{c}}$ & 0.0 & 0.1 & 0.1 & 0.0 \\
\hline Solvent content $(\%)^{\mathrm{d}}$ & 57 & 45 & 46 & 45 \\
\hline
\end{tabular}

${ }^{a}$ Values in parentheses refer to the highest-resolution shell. ${ }^{\mathrm{b}} R_{\text {meas }}$ is a multiplicity-independent measure of data quality. ${ }^{25 \mathrm{c}}$ Torsional analysis of amino acid backbone by Ramachandran plot. ${ }^{\mathrm{d}}$ Solvent content determined using Matthews coefficient calculator. ${ }^{26}$ 


\section{Additional Figures of Structural Models}
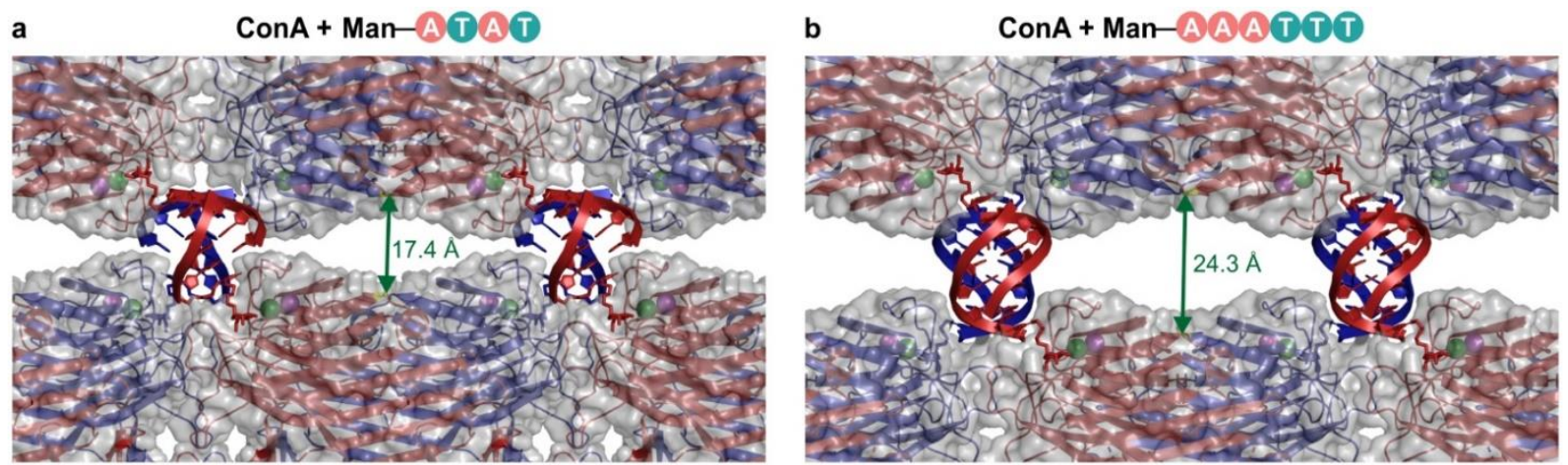

Figure S22. Comparison of the protein spacing along the $b$-direction in ConA-DNA crystals. (a, b) Protein packing of ConA with (a) Man-ATAT (structure II) and (b) Man-AAATTT (structure III). Distances labelled in green are measured between $\mathrm{C} \alpha$ atoms of D78 residues on two neighboring ConA tetramers.
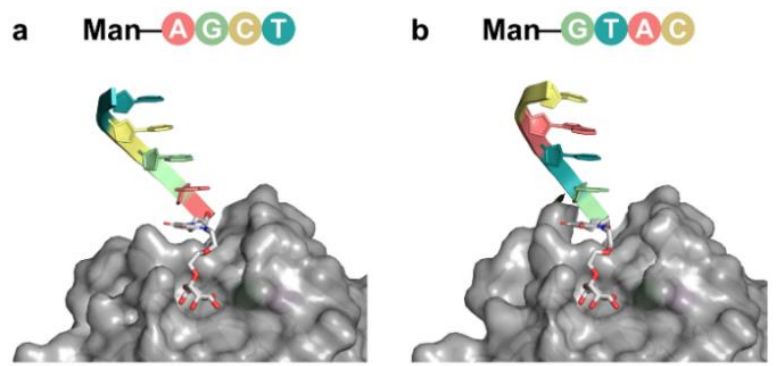

c Man-ATAT

d

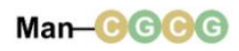

\section{e}
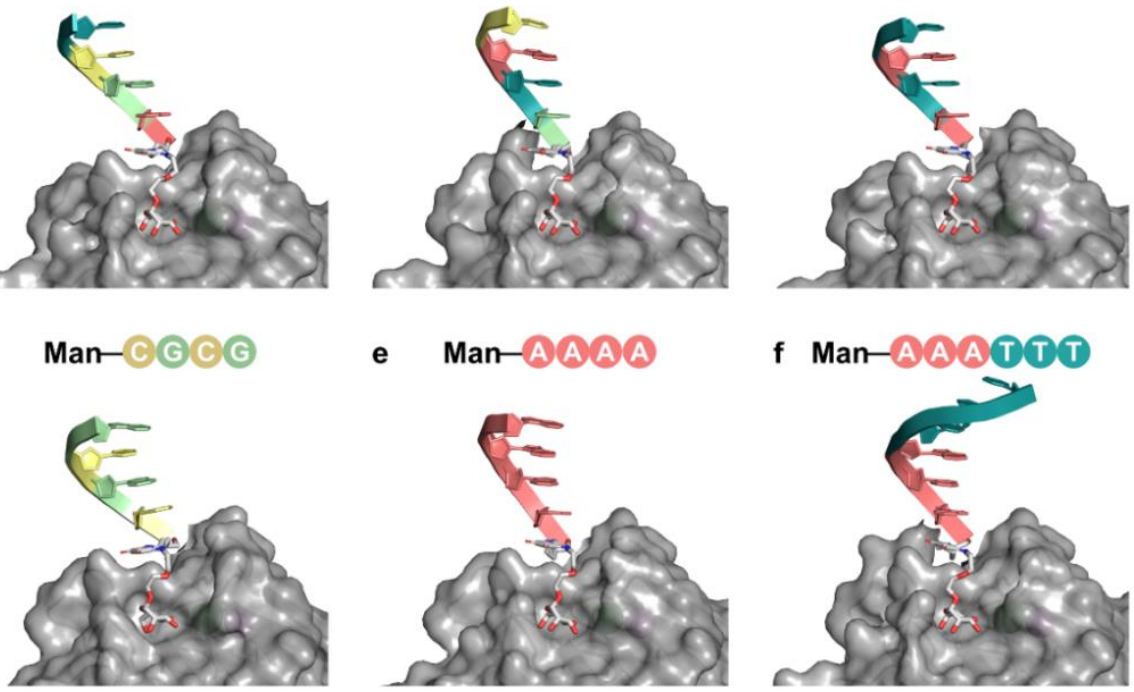

Figure S23. Comparison of DNA directionality in protein single crystals. Bound glycoconjugates with conformations apparent in electron density maps, in crystals of ConA with (a) Man-AGCT, (b) Man-GTAC, (c) Man-ATAT, (d) Man-CGCG, (e) a mixture of Man-TTTT and Man-AAAA, and (f) Man-AAATTT.
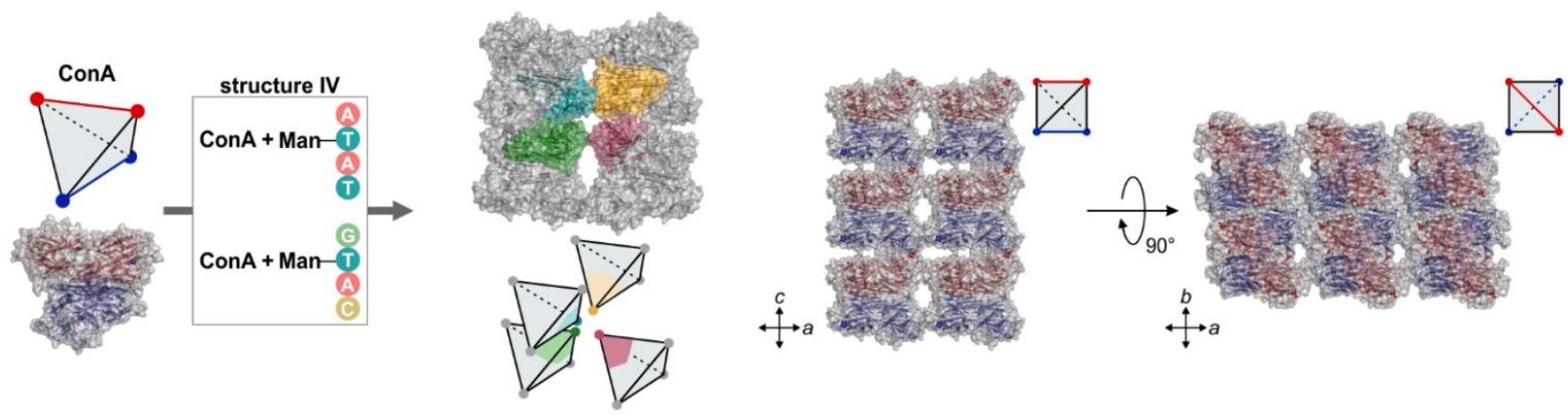

Figure S24. Crystal structure of ConA with internally-modified self-complementary DNA glycoconjugates. ConA crystallizes with self-complementary DNA (A(Man-T)AT, G(Man-T)AC) into a novel packing, structure IV. In this crystal, regions of solvent space are surrounded by the mannose-binding sites of four ConA tetramers. 

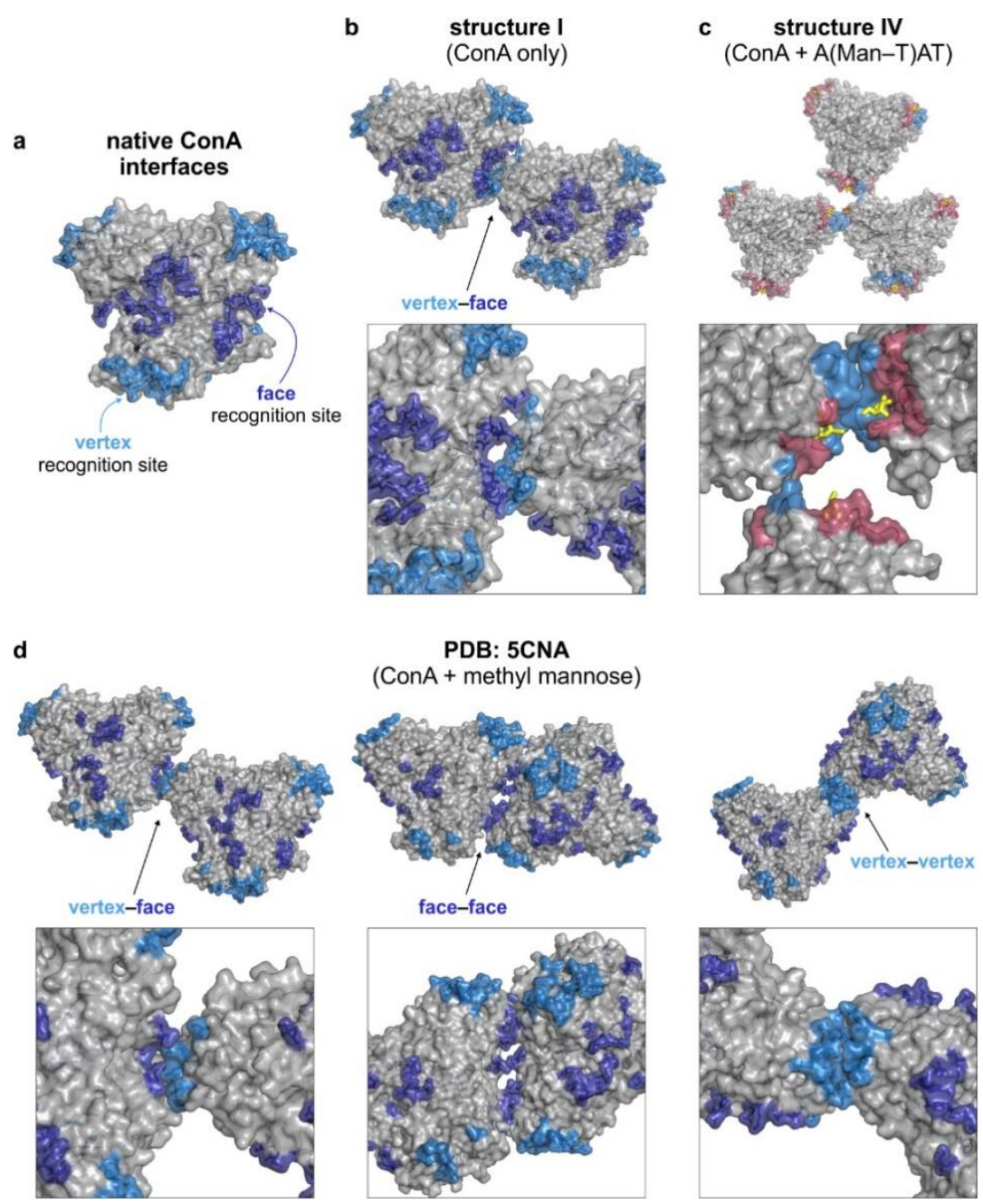

Figure S25. Interface analysis of ConA. (a,b) The crystal packing of unbound ConA in its native structure (structure I) is dominated by a single PPI between recognition sites at the tetramer face (dark blue) and vertex (light blue). The recognition site at the vertex comprises amino acid surface residues that surround the mannose binding pocket. (c) In structure IV, the binding pockets of four adjacent tetramers are directed towards a single region of solvent space, but the amino acids around the binding pocket (that drive formation of structure I) do not mediate the primary interaction in structure IV. Amino acid residues in the native vertex recognition site are colored in (c): those in blue are involved in PPIs in structure IV, while those in red are not involved in PPIs. Mannose moieties are shown in yellow. Only three tetramers around a single region of solvent space are shown for clarity; on the fourth tetramer (not shown), no residues from the vertex recognition site of structure I are involved in PPIs in structure IV. The disruption to the vertex recognition site in structure IV, compared to structure I, suggests that another favorable interaction is directing protein packing, consistent with hybridization between A(Man-T)AT glycoconjugates (Figure S26). (d) The PDB structure $5 \mathrm{CNA}^{14}$ has a very similar unit cell to structure IV $\left(P 2_{1} 2_{1} 2_{1}, a, b, c=67,124\right.$, $129 \AA$ vs $P 222_{1} 2_{1}, a, b, c=68,118,123 \AA$ ) but exhibits a very different ConA packing. Interactions between ConA tetramers in 5CNA are primarily dictated by the same vertex and face recognition sites as in the structure of native ConA (structure I, a and b), but in addition to vertex-face interactions, ConA tetramers pack via face-face and vertex-vertex interfaces. 


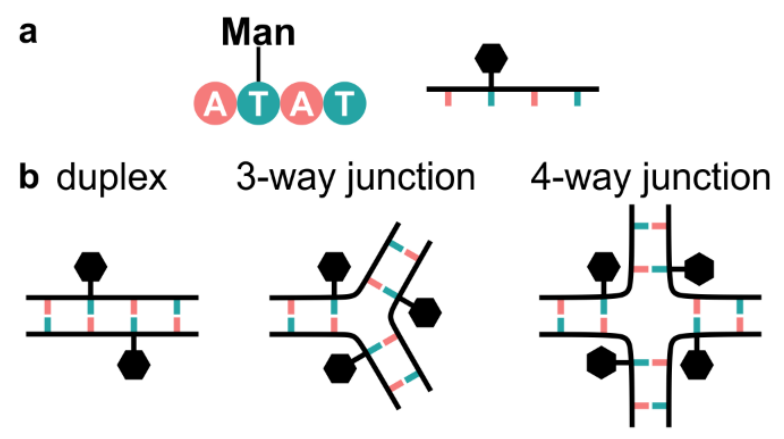

Figure S26. Hybridization modes of A(Man-T)AT. (a) Structure and schematic depiction of A(Man-T)AT. Mannose is represented by a black hexagon. (b) Possible hybridization arrangements of A(Man-T)AT that satisfy complementary base pairing.
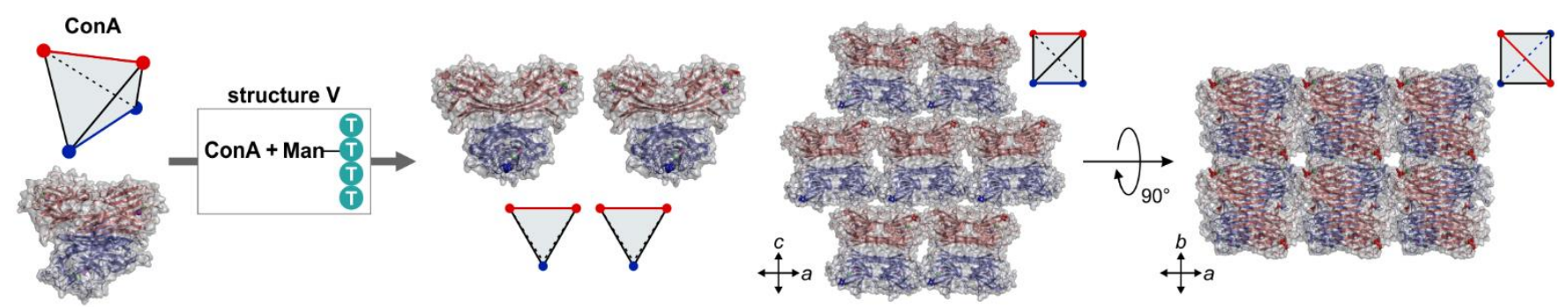

Figure S27. Crystal structure of ConA with internally-modified non-complementary DNA glycoconjugates. ConA crystallizes with non-complementary internally-modified T(Man-T)TT, G(Man-T)AC) into a known packing, structure V. The packing within structure V differs from that of structure IV (Figure S24), suggesting that the hybridization of these internally-modified oligonucleotides plays a structural role. In this crystal, regions of solvent space are surrounded by the mannose-binding sites of two ConA tetramers. The brickwork-like sheets observed in structure $\mathrm{V}$ are essentially identical to those observed in structures II and III (Figure 1b and c, respectively). However, in structure $\mathrm{V}$, these sheets are arranged in close contact along the $b$-direction.

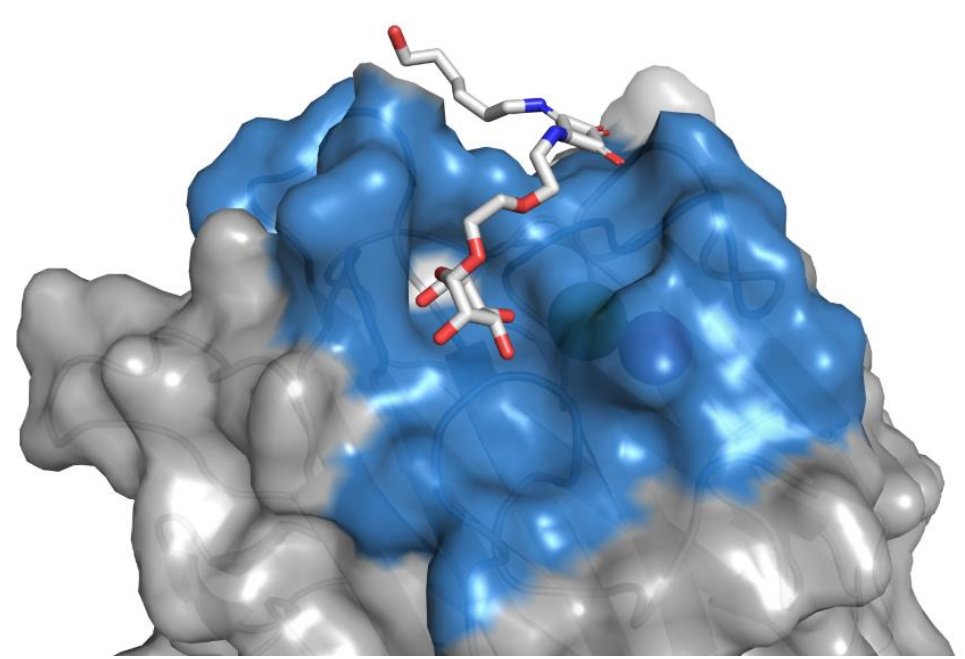

Figure S28. Amino acid surface residues surrounding the mannose-binding pocket of ConA. The amino acid residues involved in the major native PPI in structure I (shown in blue) surround the mannose-binding pocket. The mannose-squaramide portion of Man-AGCT is shown bound to the mannose-binding pocket. 


\section{References for the Supporting Information}

(1) Abellán-Flos, M.; Tanç, M.; Supuran, C. T.; Vincent, S. P. Exploring Carbonic Anhydrase Inhibition with Multimeric Coumarins Displayed on a Fullerene Scaffold. Org. Biomol. Chem. 2015, 13, 7445-7451.

(2) Zhang, S.; Moussodia, R. O.; Sun, H. J.; Leowanawat, P.; Muncan, A.; Nusbaum, C. D.; Chelling, K. M.; Heiney, P. A.; Klein, M. L.; André, S.; Roy, R.; Gabius, H.-J.; Percec, V. Mimicking Biological Membranes with Programmable Glycan Ligands Self-Assembled from Amphiphilic Janus Glycodendrimers. Angew. Chem., Int. Ed. 2014, 53, 10899-10903.

(3) Timmer, B. J. J.; Abellan Flos, M.; Monster Jorgensen, L.; Proverbio, D.; Altun, S.; Ramstrom, O.; Aastrup, T.; Vincent, S. P. Spatially Well-Defined Carbohydrate Nanoplatforms: Syntheis, Characterization and Lectin Interaction Study. Chem. Commun. 2016, 52, 12326-12329.

(4) Lindhorst, T. K.; Kötter, S.; Krallmann-Wenzel, U.; Ehlers, S. Trivalent $\alpha$-D-Mannoside Clusters as Inhibitors of Type-1 Fimbriae-Mediated Adhesion of Escherichia coli: Structural Variation and Biotinylation. J. Chem. Soc. Perkin Trans. 1 2001, 823-831.

(5) Yan, H.; Aguilar, A. L.; Zhao, Y. Preparation of Carbohydrate-Oligonucleotide Conjugates Using the Squarate Spacer. Bioorg. Med. Chem. Lett. 2007, 17, 6535-6538.

(6) Hou, S.-J.; Saksena, R.; Kováč, P. Preparation of Glycoconjugates by Dialkyl Squarate Chemistry Revisited. Carbohydr. Res. 2008, 343, 196-210.

(7) Integrated DNA Technologies. OligoAnalyzer. https://www.idtdna.com/pages/tools/oligoanalyzer (accessed April 18, 2021).

(8) Dean, B. R.; Homer, R. B. The Use of a Fluorescently Labelled Sugar to Investigate Binding by Concanavalin A. Biochim. Biophys. Acta 1973, 322, 141-144.

(9) Dessau, M. A.; Modis, Y. Protein Crystallization for X-Ray Crystallography. J. Vis. Exp. 2011, 47, e2285.

(10) Winn, M. D.; Ballard, C. C.; Cowtan, K. D.; Dodson, E. J.; Emsley, P.; Evans, P. R.; Keegan, R. M.; Krissinel, E. B.; Leslie, A. G. W.; McCoy, A.; McNicholas, S. J.; Murshudov, G. N.; Pannu, N. S.; Potterton, E. A.; Powell, H. R.; Read, R. J.; Vagin, A.; Wilson, K. S. Overview of the CCP4 Suite and Current Developments. Acta Crystallogr. Sect. D Biol. Crystallogr. 2011, 67, 235-242.

(11) Battye, T. G. G.; Kontogiannis, L.; Johnson, O.; Powell, H. R.; Leslie, A. G. W. iMOSFLM: A New Graphical Interface for Diffraction-Image Processing with MOSFLM. Acta Crystallogr. Sect. D Biol. Crystallogr. 2011, 67, 271-281.

(12) Evans, P. Scaling and Assessment of Data Quality. Acta Crystallogr. Sect. D Biol. Crystallogr. 2006, 62, 72-82.

(13) Parkin, S.; Rupp, B.; Hope, H. Atomic Resolution Structure of Concanavalin A at 120 K. Acta Crystallogr. Sect. D Biol. Crystallogr. 1996, 52, 1161-1168.

(14) Naismith, J. H.; Emmerich, C.; Habash, J.; Harrop, S. J.; Helliwell, J. R.; Hunter, W. N.; Raftery, J.; Kalb, A. J.; Yariv, J. Refined Structure of Concanavalin A Complexed with Methyl $\alpha$-D-Mannopyranoside at 2.0 $\AA$ Resolution and Comparison with the Saccharide-Free Structure. Acta Crystallogr. Sect. D Biol. Crystallogr. 1994, 50, 847-858.

(15) Matthews, B. W. Solvent Content of Protein Crystals. J. Mol. Biol. 1968, 33, 491-497.

(16) Kantardjieff, K. A.; Rupp, B. Matthews Coefficient Probabilities: Improved Estimates for Unit Cell Contents of Proteins, DNA, and Protein-Nucleic Acid Complex Crystals. Protein Sci. 2003, 12, 18651871.

(17) Murshudov, G. N.; Skubák, P.; Lebedev, A. A.; Pannu, N. S.; Steiner, R. A.; Nicholls, R. A.; Winn, M. D.; Long, F.; Vagin, A. A. REFMAC5 for the Refinement of Macromolecular Crystal Structures. Acta Crystallogr. Sect. D Biol. Crystallogr. 2011, 67, 355-367.

(18) Kovalevskiy, O.; Nicholls, R. A.; Long, F.; Carlon, A.; Murshudov, G. N. Overview of Refinement Procedures within REFMAC 5: Utilizing Data from Different Sources. Acta Crystallogr. Sect. D Struct. 
Biol. 2018, 74, 215-227.

(19) Emsley, P.; Lohkamp, B.; Scott, W. G.; Cowtan, K. Features and Development of Coot. Acta Crystallogr. Sect. D Biol. Crystallogr. 2010, 66, 486-501.

(20) Long, F.; Nicholls, R. A.; Emsley, P.; Gražulis, S.; Merkys, A.; Vaitkus, A.; Murshudov, G. N. AceDRG: A Stereochemical Description Generator for Ligands. Acta Crystallogr. Sect. D Struct. Biol. 2017, 73, 112122.

(21) Steiner, R. A.; Tucker, J. A. Keep It Together: Restraints in Crystallographic Refinement of Macromolecule-Ligand Complexes. Acta Crystallogr. Sect. D Struct. Biol. 2017, 73, 93-102.

(22) Brown, A.; Long, F.; Nicholls, R. A.; Toots, J.; Emsley, P.; Murshudov, G. Tools for Macromolecular Model Building and Refinement into Electron Cryo-Microscopy Reconstructions. Acta Crystallogr. Sect. D Biol. Crystallogr. 2015, 71, 136-153.

(23) Jamshidiha, M.; Pérez-Dorado, I.; Murray, J. W.; Tate, E. W.; Cota, E.; Read, R. J. Coping with Strong Translational Noncrystallographic Symmetry and Extreme Anisotropy in Molecular Replacement with Phaser: Human Rab27a. Acta Crystallogr. Sect. D Struct. Biol. 2019, 75, 342-353.

(24) Lebedev, A. A.; Isupov, M. N. Space-Group and Origin Ambiguity in Macromolecular Structures with Pseudo-Symmetry and Its Treatment with the Program Zanuda. Acta Crystallogr. Sect. D Biol. Crystallogr. 2014, 70, 2430-2443.

(25) Diederichs, K.; Karplus, P. A. Improved $R$-Factors for Diffraction Data Analysis in Macromolecular Crystallography. Nat. Struct. Biol. 1997, 4, 269-275.

(26) Wake Forest University Center for Structural Biology. $V_{M}$ (Matthews Coefficient) Calculator. https://csb.wfu.edu/tools/vmcalc/vm.html (accessed April 18, 2021). 